\title{
Thematische Rollen bei einer kontrastiv und derivationell ausgerichteten Beschreibung des Valenzpotentials im Deutschen und Tschechischen ${ }^{1}$
}

\section{Mojmír Muzikant und Roland Wagner}

The text discusses thematic roles previously suggested in the linguistic literature to capture the meaning of syntactic constituents related to the valency of a dominating word form. It aims at identifying an appropriate inventory of such roles which would serve as a descriptive tool for describing the lexical entries in a valency dictionary under construction. As the valency dictionary under consideration sets out to document the valency of categorially different lexical items derived from a common core unit, the roles used in the dictionary must be stable across derivational boundaries. In addition, they must suit the descriptive purpose, differentiate variants within a lexical entry and be intelligible to a wide audience of dictionary users and linguists working in different frameworks. The paper concludes in suggesting an inventory of 17 roles.

decausativization - derivation - nominalization - thematic roles - valency dictionary valency frame - valency theory

Im vorliegenden Text werden verschiedene thematische Rollen diskutiert, die in der sprachwissenschaftlichen Literatur vorgeschlagen wurden, um bestimmte Bedeutungsschattierungen von valenzgebundenen Begleitern in syntaktischen Konstruktionen zu erfassen. Ziel ist es, ein Rollenrepertoire aufzustellen, das sich zur Beschreibung der Lexikoneinträge in einem zurzeit in Entstehung begriffenen Valenzlexikon eignen würde. Da das Lexikon die Valenzalternationen im Umfeld von Valenzträgern verschiedener Wortartenzugehörigkeit dokumentieren soll, müssen die gewählten Rollen ganz spezifische Funktionen erfüllen. Neben der Anschaulichkeit, der Verständlichkeit für einen möglichst weiten Kreis von Benutzern (auch Sprachwissenschaftler, die sich verschiedenen Theorien verpflichtet fühlen) und der Unterscheidungskraft in Bezug auf die Varianten innerhalb eines Eintrags müssen die Rollen über die Derivationsgrenzen hinweg stabil bleiben, damit die gegenseitige Zuordnung der einzelnen Valenz-Realisierungsstrukturen gewährleistet ist. Am Ende des Beitrags wird ein Rollenrepertoire von 17 verschiedenen Rollen vorgeschlagen.

Aktantenrahmen -Dekausativierung - Derivation - Nominalisierung - thematische Rollen Valenzlexikon - Valenztheorie

\section{Einleitung}

Thematische Rollen bzw. deren unter verschiedenen Bezeichnungen wie „Tiefenkasus“, „semantische Rollen“, „relationale Merkmale“ firmierende konzeptuelle Äquivalente gehören seit den 1960er Jahren zu den Konstanten des linguistischen Beschreibungsrepertoires, sei es als theoretische Konstrukte im Rahmen

1 Der Beitrag ist im Rahmen des Projekts „Valenční rámce německých a českých sloves a jejich derivátů “ entstanden, das unter der Projekt-Nummer GA15-05356S von der Forschungsagentur der Tschechischen Republik (GAČR) gefördert wird. 
der verschiedenen linguistischen Theorien, sei es als deskriptive Labels zu Zwecken der (Valenz-)Lexikographie. Auch wenn die allseits bekannten Schwierigkeiten, ein konsistentes und exhaustives Rolleninventar aufzustellen, in den letzten Jahrzehnten vielfach zu einer Abkehr von thematischen Rollen im herkömmlichen Sinne geführt haben (vgl. z. B. Van Valin und LaPolla 1997: 116; Welke 2002: 95; Levin und Rappaport Hovav 2005: 51), so findet sich doch auch in aktuellen grammatischen Darstellungen oder Wörterbüchern der Bezug auf das „Agens“, das „Patiens“ oder den „Experiencer“ eines gegebenen Verbs (vgl. z. B. Eroms 2000: 181; Eisenberg 2006: 258).

Im vorliegenden Beitrag wollen wir genauer erörtern, welche Funktion thematische Rollen für die Valenzlexikographie noch heute haben können und welche und wie viele Rollen für die genauer zu bestimmenden Zwecke der Valenzlexikographie benötigt werden. Unseren Bezugspunkt bildet dabei ein in Arbeit befindliches Valenzlexikon, in dem Valenzträger aus zwei verschiedenen Sprachen (dem Deutschen und dem Tschechischen) erfasst werden sollen. Das Valenzlexikon ist derivationell organisiert und erfasst neben verbalen auch verschiedene deverbale Valenzträger (nominalisierte Infinitive, deverbale Substantive auf -ung u. ä.), deren Valenz wir von einem gemeinsamen Aktantenrahmen ableiten (vgl. Karlík 2000a; 2002 für einen ähnlichen Ansatz). ${ }^{1}$ Die Konzeption stellt natürlich spezifische Anforderungen an das gewählte Notationssystem, zu dem u. a. thematische Rollen gehören.

Im ersten Abschnitt des Beitrags wird präzisiert, welche Ziele wir in unserem Valenzlexikon bei der Verwendung von thematischen Rollen verfolgen. Vor dem Hintergrund dieser Zielsetzung sollen dann im Hauptteil des Artikels verschiedene thematische Rollen diskutiert werden, wie sie in der linguistischen Fachliteratur und älteren lexikographischen Arbeiten verwendet wurden. Die Diskussion folgt dabei einer Grobeinteilung der Rollen nach den Positionen im Aktantenrahmen, denen sie (in erster Linie) zugeordnet werden: Zunächst (Abschn. 2) werden die Rollen im Bereich des Erstaktanten (A-1) betrachtet, die sich grob unter dem Stichwort „Proto-Agens“ zusammenfassen lassen. Im folgenden Abschnitt (Abschn. 3) erfolgt die Diskussion der Rollen im Bereich des Zweitaktanten (A-2) bzw. des ProtoPatiens. Rollen, die prototypischer Weise dem Drittaktanten (A-3) zugewiesen werden, sind Gegenstand des vierten Abschnittes. Der fünfte Abschnitt beschäftigt sich schließlich mit der Peripherie des Aktantenrahmens und bietet eine Diskussion von Rollen wie „Lokativ“ oder „Final“. Das Rolleninventar, das sich im Laufe der Diskussion herauskristallisiert, wird im letzten Abschnitt in tabellarischer Form zusammengefasst.

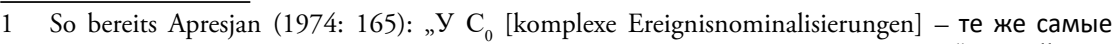
валентности, что у ключевого слова, и все они принципиально реализуемы“. Einzelheiten zur Konzeption des Valenzlexikons finden sich in Muzikant und Wagner (2016) und Wagner (in Druck). 


\section{Die Funktion von thematischen Rollen in einem derivationellen und kontrastiven Valenzlexikon}

Die Verwendung von thematischen Rollen in Valenzeinträgen ist kein Selbstzweck, sondern hat bestimmte Ziele, die unmittelbar mit den Zielen der jeweiligen Valenzbeschreibung zusammenhängen. Neben der Logik des jeweils gewählten Beschreibungssystems spielt hier auch die Zielgruppe, an die sich die Darstellung richtet, eine entscheidende Rolle. Im Folgenden erörtern wir vier thesenartig formulierteZiele einer aufRollen gestützten Beschreibung, die sich aus der Zielsetzung und dem Adressatenkreis unseres in Arbeit befindlichen Valenzlexikons ergeben.

- Thematische Rollen sollten zur leichten Unterscheidung verschiedener Varianten eines Hyperlexems sowie zur Unterscheidung verschiedener Lexeme beitragen.

Das Gesagte lässt sich anschaulich am Beispiel des Verbs räumen illustrieren (vgl. auch Helbig 1992: 168 f.). ${ }^{1}$ Das Verb kommt u. a. in Kontexten wie (1) und (2) vor:

(1) Die Mitarbeiter fuhren am Wochenende ihren zweiten größeren Einsatz und räumten und streuten in den höheren Lagen. [DeReKo]

(2) Als sie sich weigerten, den Platz zu räumen, wurden sie festgenommen. [DeReKo]

Die beiden Varianten lassen sich klar unterscheiden, wenn man der Subjektergänzung (SubE) unterschiedliche Rollen zuweist. In (1) führt der entsprechende Partizipant eine Handlung aus, für die eine Ortsveränderung dieses Partizipanten nicht konstitutiv ist. Man könnte die Mitarbeiter dementsprechend als „Agens" klassifizieren. Konstitutiv ist die Ortsveränderung des durch die Subjektergänzung spezifizierten Partizipanten dagegen für die Verbbedeutung in (2): Die Demonstranten (durch das Pronomen sie bezeichnet) weigern sich, den Platz zu verlassen, d. h. sich von einem Ort an einen anderen Ort zu bewegen. Für sich bewegende Partizipanten ist in der internationalen Forschung die Bezeichnung "Thema" geläufig (vgl. z. B. Fillmore 2003: 464, Abb. 36.2; Van Valin 2005: 54, Abb. 2.2, und Abschn. 3.3 in diesem Text). Ein Leser, der mit den Definitionen von „Agens“ und „Thema“ vertraut ist, kann bei der Verwendung der beiden Rollen-Labels den Bedeutungsunterschied zwischen (1) und (2) auf den ersten Blick erfassen. Um dieselbe Wirkung mit anderen Mitteln zu erreichen, müsste man genaue Bedeutungsparaphrasen verwenden, für

1 Helbig (1992) beschreibt die unterschiedlichen Aktantifizierungsmuster innerhalb der Variante von räumen, die wir oben unter (1) illustrieren. Die Bewegung des (in Bsp. 1 nicht realisierten) Patiens/ Themas erfasst er durch ein Merkmal [+Motion], das er allerdings nicht dem Aktanten, sondern dem Verb als Bedeutungsmerkmal zuschreibt. Die Variante, bei der das Merkmal [+Motion] nicht dem Zweit-, sondern dem Erstaktanten zugewiesen wird (oben in Bsp. 2 illustriert), berücksichtigt der Autor in seinem Mustereintrag dagegen nicht. 
die die (problematische) Festlegung eines kohärenten Beschreibungsvokabulars erforderlich wäre und die - je nach der zu paraphrasierenden Bedeutung - recht unhandlich ausfallen können.

- Durch die verwendeten thematischen Rollen sollten sich die unterschiedlichen Realisierungsstrukturen im Umfeld von Valenzträgern verschiedener kategorialer Zugehörigkeit einander eindeutig zuordnen lassen.

Der ursprüngliche Impetus der Kasus-Grammatik von Fillmore (1968) bestand in dem Bestreben, verschiedene Oberflächenstrukturen als Realisierungen desselben Kasusrahmens beschreibbar zu machen (vgl. auch Fillmore 2003: 461). So ließen sich Satzstrukturen wie Klaudia öffnet die Tür und Die Tür öffnet sich als Realisierungen des Kasusrahmens „(Agens) Patiens“ auffassen; über eine Rollenhierarchie wird sichergestellt, dass das Patiens nur dann in der Subjektposition realisiert wird, wenn die Realisierung des fakultativen Agens unterbleibt. ${ }^{1}$ Gleichzeitig ist es möglich, die Nominalgruppe (NG) die Tür in beiden Sätzen als Realisierung desselben Tiefenkasus „Patiens“ (bei Fillmore „Objektiv“) aufzufassen, was die sehr ähnlichen Beschränkungen bei der Besetzung der entsprechenden Positionen und die sehr ähnlichen thematischen Eigenschaften der in diesen Positionen spezifizierten Partizipanten (Zustandsänderung) elegant erklärt.

Das Modell von Fillmore erfüllt damit eine Grundvoraussetzung für die Verwendung als Notationssystem in einem derivationell konzipierten Valenzlexikon: Es ermöglicht, einen Bezug zwischen den ValenzRealisierungsstrukturen in verschiedenen kategorialen Kontexten herzustellen. Über die Rolle „Patiens“ könnte z. B. die adnominale Genitivposition in einer NG wie das Öffnen der Tür auf die Objektposition des transitiven und die Subjektposition des intransitiven Verbs bezogen werden. Man beachte, dass dieselbe Wirkung nicht - oder nur mit erhöhtem technischen Aufwand - durch die Verwendung von morphosyntaktisch definierten Ergänzungsklassen wie etwa in $[\mathrm{VALBU}]^{2}$ erzielt werden kann.

1 Der Kasus-Rahmen für open findet sich in Fillmore (1968) als Punkt (45) in Kap. 3 und wird mit O (I) (A)“ (obligatorischer Objektiv sowie fakultativer Instrumental und Agentiv) angegeben. Die Hierarchie wird in Punkt (55), ebd., formuliert. Eine ähnliche Notation schlägt Ágel (2000: 124) zur Erfassung von labilen Verben wie brechen vor.

2 In [VALBU] (Schumacher et al. 2004: 30) werden Ergänzungsklassen wie Nominativergänzung (NomE), Akkusativergänzung (AkkE) oder Präpositivergänzung (PräpE) verwendet, deren Bezeichnungen auf morphosyntaktische Realisierungsmerkmale Bezug nehmen und damit prinzipiell ungeeignet für die im Haupttext oben genannten Ziele sind (der adnom. Genitiv ist z. B. keine Akkusativergänzung). Man muss jedoch zugestehen, dass die Autoren von [VALBU] die morphosyntaktisch motivierten Bezeichnungen ausdrücklich nur als mnemotechnische Abkürzungen verstanden wissen wollen und explizit von einer morphozentrischen Bestimmung der Klassen Abstand nehmen (ebd., S. 28 f.). 
- Die verwendeten thematischen Rollen sollten eine eindeutige Zuordnung der Valenz-Realisierungsstrukturen in einer Sprache zu den ValenzRealisierungsstrukturen in einer anderen Sprache gewährleisten.

Hier gilt im Prinzip dasselbe, was im vorangegangenen Punkt zur kategorienübergreifenden Identifizierung und gegenseitigen Zuordnung von Valenz-Realisierungsstrukturen gesagt wurde. Da Übersetzungsäquivalente in zwei verschiedenen Sprachen per definitionem dieselben oder zumindest ähnliche thematische Rollen implizieren, lässt sich über Rollen eine sprachübergreifende Zuordnung der Realisierungsstrukturen erreichen, ohne dabei auf die morphosyntaktische Form Bezug zu nehmen, die ja in verschiedenen Sprachen nicht identisch sein muss. Betrachten wir zur Illustration z. B. das deutsch-tschechische Verbpaar entziehen und zbavovatlzbavit. Wie die beiden bedeutungsäquivalenten Sätze in (3) zeigen, werden im Valenzfeld des deutschen Verbs Nominalgruppen (NGs) im Nom, Akk und Dat realisiert, im Valenzfeld des tschechischen Verbs dagegen NGs im Akk und Gen (die NG im Nominativ bleibt implizit). ${ }^{1}$

(3) a. Sie haben dem Direktor die Funktion entzogen.

b. Zbavili ředitele funkce. entziehen.3PL.Prät Direktor.Akк.Sg Funktion.Gen.Sg

Würde man nun die Zuordnung der Aktanten streng nach morphosyntaktischen Merkmalen vornehmen, müsste man die NG die Funktion (AkkE) im Deutschen der NG ředitele (AkkE) ,Direktor` im Tschechischen zuordnen. Dies stellt natürlich eine Fehlanalyse dar, da ředitele (AkkE) der NG dem Direktor (DatE) zugeordnet werden muss, will man die Bedeutungsäquivalenz reflektieren. Es gibt verschiedene Möglichkeiten, dieses Problem zu lösen. Eine Möglichkeit, die hier zur Diskussion steht, ${ }^{2}$ wäre, die Zuordnung nach thematischen Rollen vorzunehmen. In diesem Falle wäre sowohl der NG ředitele als auch der NG dem Direktor dieselbe Rolle, z. B. „(negativer) Rezipient“, zuzuordnen, womit beide NGs als Realisierungsstrukturen desselben Aktanten und damit gleichzeitig als strukturelle Übersetzungsäquivalente ausgewiesen wären. Zu diesem Zweck müssen dann natürlich genügend Rollen

1 Zum tsch. Verb, vgl. [VALLEX, S. 474], zum dt. Verb z. B. [DUDEN, S. 934]. Dass es daneben im Deutschen ein weiteres Äquivalent zu zbavovatlzbavit (nämlich entheben) gibt, bei dem die Verteilung der Rollen auf die syntaktischen Positionen genauso erfolgt wie im Tschechischen, ist für die Illustration des Problems unerheblich.

2 Zwei alternative Möglichkeiten, die an dieser Stelle nicht genauer diskutiert werden können, wollen wir nur kurz andeuten: (a) Man könnte sich auf die Selektionsbeschränkungen stützen, die die Besetzung der Valenzpositionen regeln, im vorliegenden Fall [+anim] für die DatPosition im Deutschen und die Akk-Position im Tschechischen. Auf die Aussagekraft solcher Selektionsbeschränkungen verlassen sich z. B. Helbig und Schenkel (1969). (b) Die Zuordnung könnte über die Reihenfolge der Aktanten im Aktantenrahmen erfolgen, so wie sie im Text oben angesetzt wurde. Dabei würden im deutsch-tschechischen Vergleich Dat/Akk und Akk/Gen zur Deckung kommen und als Realisierungsstrukturen desselben Aktanten identifiziert. 
im Rollenrepertoire zur Verfügung stehen, um die NGs ředitele bzw. dem Direktor thematisch von den beiden anderen Begleitern unterscheiden zu können.

- Die verwendeten Rollenlabels sollten problemlos im Rahmen verschiedener theoretischer Ansätze interpretierbar sein.

Da Rollen im Rahmen der unterschiedlichsten grammatischen Modelle verwendet werden, sind sie in der linguistischen Community allgemein bekannt und würden es Linguisten verschiedenster theoretischer Ausrichtung ermöglichen, die empirischen Ergebnisse unserer korpusbasierten Untersuchungen, die im geplanten Valenzlexikon dokumentiert werden sollen, zu rezipieren und für ihre jeweiligen Konzeptionen nutzbar zu machen. Um die Rezeption zu erleichtern, sollten die verwendeten Bezeichnungen gängige Rollenlabels sein, die von allen Interessierten verstanden werden (auch wenn sie die dahinterstehenden theoretischen Konstrukte vielleicht ablehnen). Diese letzte Zielsetzung zwingt zu Kompromisslösungen, bei denen Überlegungen zur Konsistenz des verwendeten Systems gegen den Bekanntheitsgrad der eingeführten Rollenlabels abgewogen werden müssen. So mag die Rolle „Mutativ“, die sich etwa (in Anschluss an Engel 2009) bei Vázquez (2011: 177) findet, zwar kohärent in die Konzeption der zitierten Arbeit integriert sein; das Rollenlabel ist aber weitgehend unbekannt und daher - ungeachtet der prinzipiellen Arbitrarität von Bezeichnungen für Rollenkonzepte - wohl eher zugunsten von bekannteren Rollenlabels wie „Patiens“ abzulehnen.

Nachdem wir die Funktionen skizziert haben, die thematische Rollen im Rahmen unseres Valenzlexikons erfüllen sollten, können wir zur kritischen Durchsicht der Literatur und zur Bewertung der Vorschläge hinsichtlich des Rolleninventars kommen.

\section{Rollen im Bereich des Erstaktanten}

Im Bereich des Erstaktanten (A-1) bzw. der Subjektergänzung (SubE) ist das am weitesten verbreitete Rollenlabel „Agens“. In diesem Zusammenhang stellen sich zwei Fragen: (a) Wie eng ist das Konzept „Agens“ aufzufassen? Sollte die Rolle auf Partizipanten, die willentlich und zielgerichtet eine bestimmte Handlung ausführen, eingeschränkt werden oder ist eine prototypische Konzeption vorzuziehen, die auch Agentien zulässt, denen bestimmte agentive Eigenschaften fehlen? Im zweiten Fall könnte man mit einer einzigen agentiven Rolle auskommen, im ersten Fall müssen ggf. weitere Rollen im Proto-Agens-Bereich festgelegt werden, da ja nicht jede SubE den willentlich und zielgerichtet agierenden Partizipanten einer Handlung bezeichnet. In diesem Zusammenhang wäre dann auch (b) zu fragen, ob als SubE in nicht-abgeleiteten (d. h. aktivischen, nicht-modalisierten, nicht-reflexiven) Konstruktionen auch Rollen des Patiens-Spektrums zugelassen sind oder ob man solche Rollen auf die tieferen Valenzpositionen beschränken sollte. 
Im Folgenden konzentrieren wir uns auf die erste Frage. Die zweite Frage kann hier aus Platzgründen nur kurz gestreift werden, eine genauere Erörterung muss aus Platzgründen einem späteren Artikel vorbehalten bleiben. Als Ausgangspunkt der Diskussion wählen wir das Rolleninventar, das Ulrich Engel in seiner neu bearbeiteten Deutschen Grammatik anbietet (Engel 2009: 189-196) und das auch dem kontrastiven Valenzlexikon Deutsch - Bosnisch/Kroatisch/Serbisch (Djordjević und Engel 2009, insb. S. 10-12, kurz [BKS]), zugrunde liegt.

\subsection{Agens und Effektor}

Engel (2009) geht von einem prototypischen Rollenkonzept aus und verwendet (neben den beiden nicht auf Partizipanten bezogenen Rollen „Klassifikativ“ und „Lokativ“) nur zwei thematische Rollen („Agentiv“ und „Affektiv“), die somit an die beiden Proto-Rollen bei Dowty (1991) oder die Makro-Rollen bei Van Valin und LaPolla (1997) erinnern. Beide „Makro-Rollen“ können durch die Merkmale „fer“ (Ferens/Träger), „mut“ (Mutativ/sich verändernder Partizipant) und „eff“ (Efficient/ entstehender Partizipant) weiter feinklassifiziert werden. „Ferens“ ist dabei zumindest im Bereich des Agentiv - nicht nur Vorgangs- oder Zustandsträger im herkömmlichen Sinne (wie z. B. bei Helbig und Buscha 1999: 69 und in den älteren Arbeiten von Engel selbst, z. B. Engel 1991:360), ${ }^{1}$ sondern häufig auch der Träger einer Handlung. Als Handlungsträger kann $\mathrm{AGT}_{\mathrm{fer}}$ das Subjekt sowohl von intransitiven (arbeiten) als auch von transitiven (nehmen, schreiben, zerbrechen) Handlungsbzw. Tätigkeitsverben und von Kausativa sein. Die prototypische Auffassung von Agentivität kommt darin zum Ausdruck, dass Engel von Willentlichkeit (verlieren), Kontrolle (frieren, leben) und letztendlich sogar von Eigenaktivität (bedeuten, wie in Die Ablehnung bedeutet Krieg [BKS, S. 118]) abstrahiert. Mutative Agentien kommen in [BKS], soweit wir sehen können, vorwiegend mit Bewegungsverben (z. B. abfahren, ausziehen, laufen, fahren, fliegen, folgen, kommen, landen, schwimmen, umsteigen, umziehen, überholen, verfolgen, wandern) vor. Die anderen in [BKS] angeführten Fälle, sofern sie wirklich als agentiv und mutativ ${ }^{2}$ betrachtet werden können, sind

1 Als Vorgangsträger würde nach herkömmlicher Auffassung wohl der Subjekt-Partizipant von Verben wie abnehmen, sich ändern, sich teilen, wachsen oder (zer)brechen (intr.) bewertet werden, der in [BKS] unter AGTmut subsummiert wird. Wir betrachten die entsprechenden Rollen - wegen der fehlenden Agentivität (auch im prototypischen Sinne) - als Patiens. Überraschenderweise klassifizieren Engel und Koll. den Subjekt-Aktanten der Verben sich drehen, fallen, stürzen und werden, der sonst wohl ebenfalls als Vorgangsträger betrachtet würde, nicht als AGTmut, sondern als Affektiv (AFFfer). Da in keinem der herangezogenen Texte ([BKS] und Engel 2009) genaue Abgrenzungskriterien genannt werden, muss offenbleiben, ob es sich um eine nur auf den ersten Blick überraschend wirkende oder aber um eine inkonsistente Klassifizierung handelt.

2 Als Test für Mutativität ließe sich die Bildbarkeit von Resultativkonstruktionen verwenden. Nach diesem Test wäre z. B. die SubE von sich an etw. machen $\left({ }^{*}\right.$ Ich bin an etw./daran gemacht) oder sich beeilen $\left({ }^{*} D u\right.$ bist beeilt) nicht mutativ, obwohl sie in [BKS] als AGTmut eingestuft wird. 
reflexiv $^{1}$ (z. B. sich (von der Welt) abschließen, sich ändern, sich aufregen, sich beeilen, sich berubigen, sich erholen, sich gewöhnen, sich legen, sich an etw. machen, sich sammeln, sich setzen, sich stellen, sich teilen, sich üben, sich verändern, sich verbessern, sich verlieren, sich verspäten). Dies ist $\mathrm{u}$. E. kein Zufall und geht offensichtlich auf reflexiv bewirkte Rollen-Akkumulation zurück, worauf wir in Abschn. 3.3 bei der Behandlung der Rolle „Thema“ zurückkommen. Für den effizierten Agentiv (AGT eff $_{\text {) }}$ gilt Ähnliches wie für $\mathrm{AGT}_{\mathrm{fer}}$ : Die Rolle deckt das herkömmlicherweise unter „Vorgangsträger" subsumierte Rollenspektrum ab (anfangen, sich ereignen, sich finden, geschehen, platzen, sterben, verhungern, sich wiederholen), charakterisiert aber nicht einen sich verändernden, sondern einen neu entstehenden oder verschwindenden Partizipanten. Weitere in der Literatur verbreitete Rollen wie „Experiencer“, „Stimulus“, „Kausator“, „Instrument“, „Lokativ“ (in Subjektfunktion) oder „Thema“ (vgl. z. B. Van Valin und LaPolla 1997: 85 f.; Grepl und Karlík 1998: 38 f.; Eroms 2000: 180-183; Fillmore 2003: 464; ein Überblick findet sich in Welke 2011: 142 f.) kommen bei Engel nicht vor.

Zunächst ist anzumerken, dass ein gewisses $\mathrm{Ma}$ an Abstraktion von den prototypischen Agens-Eigenschaften wie „willentliches, zielgerichtetes Handeln“ wohl sinnvoll ist (vgl. DeLancey 1984; Van Valin und Wilkins 1996). Wie Van Valin und Wilkins (1996) darlegen, entsteht die Interpretation, dass eine Handlung willentlich und zielgerichtet ausgeführt wird, bei den meisten sprachlichen Prädikaten erst in Folge einer konventionellen Implikatur, da belebten und v. a. menschlichen Partizipanten generell willentlich gesteuertes Handeln unterstellt wird. Die prototypische Agens-Eigenschaft „willentlich“, „absichtlich“ oder „zielgerichtet" ist somit im Allgemeinen vom Kontext abhängig und kann unter geeigneten Bedingungen aufgehoben werden, vgl. z. B. Er hat sein Opfer schwer verletzt (vermutl. absichtlich) vs. Er hat sich an einem Messer verletzt (unabsichtlich). In manchen Fällen kann offen bleiben, ob die Handlung absichtlich oder unabsichtlich ausgeführt wurde, z. B. Er hat mich gestoßen (vgl. dazu auch Sgall, Hajičová und Panevová 1986: 114). Die Bedeutungskomponente „willentlich“ scheint also nicht sprachlich kodiert (oder, wie Welke, 2002: 11, sagen würde, „formalsyntaktisch angewiesen") zu sein und sollte daher bei der Festlegung der thematischen Rolle keine Rolle spielen. Entsprechend wird man auch bei Valenzträgern, die für A-1 generell unabsichtliches Handeln implizieren (z. B. verlieren), ${ }^{2}$ die Rolle „Agens“ ansetzen.

1 Ausnahmen sind aufstehen, badenlduschen, kennenlernen, lernen, schließen (wie in Die Geschäfte schließen) und wenden (wie in Der Wagen wendete).

2 Dass auch bei verlieren für A-1 ein gewisses Maß an Agentivität impliziert ist, zeigt die Bildbarkeit von Passivkonstruktionen: Wo wurde der Pass verloren? [BKS, S. 610]. Bei einem Verb wie bekommen würde man für A-1 dagegen keine Agensrolle ansetzen, da *Wurde das Päckchen bekommen? ungrammatisch ist. Bei verlieren liegt allerdings auch die Lösung nahe, den Erstaktanten als negativen „Rezipienten“ oder „Ursprungsort“ zu klassifizieren; ggf. könnte man Rollen-Akkumulation („Agens-Rezipient“) annehmen, vgl. Abschn. 3.3. 
Damit soll nun allerdings nicht gesagt werden, dass jeder Partizipant, der in der Subjektposition von dynamischen Verben realisiert wird, automatisch als (ggf. wenig prototypisches) Agens zu betrachten ist. Im Unterschied zu Engel (2009) und zur Prager Dependenzgrammatik (Sgall, Hajičová und Panevová 1986), aber in Anschluss an Helbig und Buscha (1999), Welke (2011) und die Fillmore'sche Tradition betrachten wir den Subjekt-Aktanten von Vorgangsverben wie wachsen, sich öffnen oder sterben nicht als Agens, sondern weisen ihm eine nicht-agentive Rolle zu. Diese nicht-agentive Rolle würden wir gemäß der Definition ,Partizipant, der einer Zustandsänderung unterliegt' (vgl. Fillmore 2003: 464, Abb. 36.2) - nunmehr allerdings entgegen der in Helbig und Buscha (1999) zum Ausdruck kommenden germanistischen Tradition - als „Patiens" bezeichnen.

Differenziert man innerhalb der SubE zwischen (ggf. wenig prototypischem) Agens und Nicht-Agens, dann stellt sich natürlich die Frage, wo genau die Grenze verläuft. Gibt es außer den typischen Agens-Eigenschaften „willentlich“, „zielgerichtet" oder "kontrolliert" weitere thematische Eigenschaften, die für die Zuweisung der Agens-Rolle hinreichend sind? Levin und Rappaport Hovav (1995: 91) stützen ihre Verbklassifizierung (in einem anderen Zusammenhang) nicht auf das Agens-Merkmal „Kontroll““, sondern auf die Unterscheidung von intern und extern verursachten Sachverhalten. Verben wie stinken, glühen oder blubbern gehören nach dieser Klassifizierung zur ersten Klasse, da der in der Verbbedeutung beschriebene Sachverhalt durch eine dem Subjekt-Partizipanten inhärente Eigenschaft oder Aktivität hervorgerufen wird und nicht durch das Einwirken eines weiteren, ggf. nicht aktantifizierten externen Partizipanten. ${ }^{3}$ Die Eigenschaft, unmittelbare Ursache eines Geschehens zu sein, begründet nach der bei Levin und Rappaport Hovav (1995: 135) formulierten Linking-Regel den Status eines „externen Arguments“, d. h. (in unserer Terminologie) des Erstaktanten (A-1).

Die Klassifizierung von Levin und Rappaport Hovav weist Berührungspunkte mit dem völlig anderen Ansatz von Van Valin und Kollegen auf. In Van Valin und LaPolla (1997) und Van Valin (2005) werden thematische Rollenlabels definiert, die sich aus der semantischen Dekompositionsstruktur der Valenzträger herleiten. Verben wie stinken, glühen oder blubbern enthalten ein Aktivitätsprädikat, da sie dynamische Situationen (nachprüfbar anhand der Kombinierbarkeit mit Adverbien der Intensität wie stark, heftig, gewaltig) ohne inhärente zeitliche Grenze (nachprüfbar durch die Kombinierbarkeit mit Adverbialen der Zeitdauer wie eine Stunde lang) bezeichnen (Van Valin und LaPolla 1997: 94 f.). Das erste Argument eines Aktivitätsprädikats hat wiederum privilegierten Zugang zur ersten Makrorolle „Actor“, die wir mit unserem Erstaktanten (A-1) in Beziehung setzen.

Für die Abgrenzung der verallgemeinerten Agens-Rolle von anderen Rollen, die nicht mehr unter das allgemein gefasste Agens-Konzept fallen, scheinen also

3 Zum Konzept der „Aktantifizierung“ (urspr. nach Wotjak) s. Welke (1988: 53-57) und die dort genannte Literatur. „Nicht aktantifiziert“ bedeutet so viel, wie ,implizit mitgedacht, aber nicht im Aktantenrahmen enthalten'. 
Eigenschaften wie „unmittelbarer Urheber des Sachverhaltes“ und „Eigenaktivität“ relevant zu sein. Wie man terminologisch mit den oben referierten Feststellungen umgehen soll, ist dann allerdings eine andere Frage. Levin und Rappaport Hovav (1995: 138-142) ordnen die oben genannten Verben einer speziellen Gruppe mit der Bezeichnung „Emissionsverben“ zu, die die beiden Autorinnen explizit als nicht-agentiv betrachten. Auch Van Valin und Kollegen reservieren den Begriff „Agens“ für willentlich und zielgerichtet handelnde, belebte Partizipanten. Der Erstaktant von Emissionsverben wäre demnach kein Agens, sondern Träger der verbgruppenspezifischen Rolle „Emitter“ (Van Valin und LaPolla 1997: 115; Van Valin 2005: 55). Ein „Emitter“ ist dabei ein Spezialfall von „Effektor“, d. h. der thematischen Relation, die das erste Argument eines Aktivitätsprädikats zur Gesamtbedeutung des Valenzträgers hat.

$\mathrm{Da}$ „Emitter“ für unsere Zwecke zu feinkörnig' ${ }^{1}$ wäre, „Effektor“ aber außerhalb der von Van Valin begründeten Rollen- und Referenzgrammatik als Rollenlabel praktisch unbekannt ${ }^{2}$ ist, sehen wir keine andere Möglichkeit, als bei der traditionellen Bezeichnung „Agens“ zu bleiben, auch wenn wir, wie gesagt, die mit dieser Bezeichnung verbundenen Konnotationen wie „willentlich handelnd“, „zielgerichtet“, „belebt“ usw. zurückweisen. Damit wären die kursiv hervorgehobenen Ergänzungen in (4) Agentien, nicht aber die Ergänzungen in (5), da hier die Komponente „Eigenaktivität“ bzw. „intern verursacht“ fehlt:

(4) Wieso schreiben Menschen Bücher? [DeReKo]

Frau Jung verspricht sich dreimal beim Wort ,Physiognomie‘. [VALBU, S. 802]

Das Pferd schwitzt am ganzen Körper. [BKS, S. 504]

Der Blitz hat die Scheune getroffen. [VALBU, S. 724]

(5) Das Mädchen ist im vergangenen Jahr acht Zentimeter gewachsen. [VALBU, S. 822]

Die Welt hat sich seit diesen Tagen fühlbar verändert. [BKS, S. 589]

Die Ablehnung bedeutet Krieg. [BKS, S. 118]

Eine Verwendung des Labels „Agens“, die „Quasi-Agentien“ (DeLancey 1984: 208) miteinschließt, mag zwar auf Leser, die die Einschränkung des Begriffes auf den Prototyp gewohnt sind, irritierend wirken, lässt sich aber mit Blick auf den noch weniger restriktiven Gebrauch des Labels AGT in der weit verbreiteten Grammatik von Engel (2009) sowie mit dem Hinweis auf den in der Fachliteratur inzwischen geläufige Begriff „Proto-Agens“ (Dowty 1991) rechtfertigen.

1 Auf der untersten Ebene der Klassifizierung führen Van Valin und LaPolla (1997: 127, Abb. 3.2) 37 Rollenlabels an, in Van Valin (2005: 55, Tab. 2.4) sind es gar 40. Da beide Listen nur zur Illustration des Ansatzes dienen, ließe sich das Inventar - je nach untersuchter Verbgruppe - nahezu beliebig erweitern.

2 In Tschechien besteht zudem Verwechslungsgefahr mit dem völlig anders definierten Rollenlabel „Effekt“", das seit den 1980er Jahren im Rahmen der Prager Dependenzgrammatik (Sgall, Hajičová und Panevová 1986 et passim; jüngst auch in Panevová et al. 2014) verwendet wird. 


\subsection{Vorgangs- und Zustandsträger (Ferens)}

Halten wir als Zwischenergebnis der Diskussion fest, dass wir wie Engel (2009) einen sehr weit gefassten Agens-Begriff verwenden, im Unterschied zu Engel (2009) allerdings Vorgangsträger bzw. „Patienten“ ohne Eigenaktivität von diesem AgensBegriff ausschließen. Benötigen wir daneben noch weitere Rollen im A-1-Bereich? Ein erster Hinweis, dass dem so ist, ergibt sich bereits aus der kurzen Anmerkung zur Passivierbarkeit im vorangegangenen Abschnitt (Fußnote). Die Liste der nicht passivfähigen Verben, die Helbig und Buscha (1999: 172 f.) anführen, enthält Verben wie ähneln, gefallen, passen zu, hängen an oder aussehen, die trotz personalem A-1 mit dem Merkmal [+hum] nicht passivfähig sind. Hier liegt der Verdacht nahe, dass die fehlende Dynamik des benannten Sachverhalts für dieses grammatische Verhalten verantwortlich ist. In einem rollenbasierten System sollte dieser Umstand in der Wahl einer spezifischen thematischen Rolle zum Ausdruck kommen, an der man dann die mangelnde Passivierbarkeit festmachen könnte. ${ }^{1}$ Hier bietet es sich an, die Rolle „Zustandsträger“ mit Engel (1991:360) als „Ferens“ (FER) zu etikettieren. Unter dasselbe Rollenlabel könnte man Partizipanten subsumieren, die Träger einer Besitzrelation (Petra hat ein Schloss in den Bergen) oder einer lokalen Relation (Brünn liegt an der Schwarzawa) sind.

Ein weiterer Grund, die Rolle „Ferens“ - besonders in einem derivationell ausgerichteten Valenzlexikon - $\mathrm{zu}$ berücksichtigen, ergibt sich aus aktionsartbedingten Bildungsbeschränkungen für bestimmte Ableitungen. So ist schon lange bekannt, dass Infinitivnominalisierungen sensibel auf statische Semantik reagieren. Die Bildbarkeit von nominalisierten Infinitiven, soweit diese wirklich mit einer komplexen Ereignisstruktur ausgestattet sind, unterliegt bei Zustandsverben deutlichen Beschränkungen, vgl. Blume (2004: 44, 112) und ähnlich bereits Schippan (zit. bei Sandberg 1976: 92 f.): ${ }^{2}$

(6) a. *beim Einnehmen der Seite durch den Schrank [zit. aus Sandberg 1976: 92]

b. 'Das Besitzen von Cannabis ist strafbar. [konstruiert]

Zur Erfassung der entsprechenden Regularitäten könnte man sich auf die Rolle „Ferens“ im Aktantenrahmen des jeweiligen Valenzträgers beziehen.

Die Einbeziehung einer Rolle „Ferens“ / „Zustandsträger" bringt aber auch gewisse Komplikationen mit sich, von denen an dieser Stelle wenigstens zwei genannt

1 So merkt z. B. Engel (2009: 191) an, dass dem Passiv „,[E]ine wichtige Rolle bei der Ermittlung des AGENTIVs [zu]kommt". Im Rahmen des Systems von Engel (2009) ist diese Aussage allerdings irreführend, da der Autor ja für die Subjektergänzung einheitlich AGT ansetzt und somit das Passiv für die Ermittlung der Rolle AGT bei Engel nicht die geringste Rolle spielt. Dies lässt sich leicht anhand einer großen Zahl von Verben (z. B. abnehmen, Gewicht verlieren', einschlafen, frieren, zu Eis werden', wachsen oder zerbrechen, in Stücke zerfallen', in [BKS] alle mit AGT notiert) zeigen, die laut Engel AGT implizieren, obwohl sie gerade nicht passivfähig sind.

2 Sandberg zitiert die Dissertation von Schippan aus dem Jahre 1967, die uns leider nicht zugänglich war. Ähnliche Überlegungen finden sich in Schippan (1968). 
werden sollen. Zum einen ist der Unterschied zwischen Zustandsverben und dynamischen Verben mit eingeschränkter Agentivität und damit zwischen „Ferens“ und (untypischem) „Agens“ notorisch vage. Ob es sich bei ähneln, blühen, bluten, kränkeln oder schlafen um einen Zustand oder eher um eine nicht willentlich gesteuerte Aktivität handelt, ist nicht auf den ersten Blick klar. Die Anwendung verschiedener Tests liefert hier häufig undeutliche oder widersprüchliche Ergebnisse. Betrachtet man die Passivierbarkeit nicht als die zu erklärende Variable, sondern direkt als Testkontext, vgl. (7), wären ähneln und blühen statisch (wobei allerdings bei blühen das Merkmal [-hum] als Störgröße zu berücksichtigen ist). Bei bluten und kränkeln ${ }^{1}$ fällt der Test zwiespältig aus, schlafen wäre eher eine Aktivität als ein Zustand.

(7) Es wird *geähnelt / *geblüht / 'geblutet / "gekränkelt / geschlafen.

Verwendet man, wie in Van Valin und LaPolla (1997) und Van Valin (2005) vorgeschlagen, dynamische Adverbien als Testrahmen, dann ist nur blühen zustandsverdächtig, vgl. (8). Das Verb ähneln, das intuitiv einen Zustand bezeichnet und offenbar deshalb den Passivierungstest nicht besteht, wäre dagegen als dynamisch zu beurteilen. Die Ergebnisse des Tests hängen allerdings von der Wahl des jeweiligen Adverbs $\mathrm{ab}^{2}$ und erfordern daher eine differenziertere Bewertung als an dieser Stelle möglich ist.

(8) a. Sie ähnelt ihm stark.

b. "Sie Wiese blüht heftig / stark / intensiv.

c. Er blutet heftig / stark.

d. Er kränkelt stark.

e. Sie schläft tief und fest.

Im gegenwärtigen Zusammenhang geht es nicht darum, zu einer schlüssigen Abgrenzung der Zustandsverben von Aktivitätsverben zu gelangen. Es sollten lediglich die Möglichkeiten und Probleme der Abgrenzung vorgeführt werden. Zusätzlich zu diesem eher praktischen Problem ergibt sich aber noch ein weiteres, theorieabhängiges und damit prinzipielles Problem, für das wir leider keine Lösung anzubieten haben. Betrachten wir dazu das Verb abreißen in verschiedenen (von uns konstruierten) grammatischen Kontexten:

1 In [DeReKo, abgerufen im Oktober 2016] finden sich 58 gültige Treffer mit dem Verb bluten in Passivkonstruktionen. Völlig unauffällig erscheint uns die Konstruktion dennoch nicht, daher das Fragezeichen bei der Bewertung. ?Es wird geblutet ist aber wohl dennoch deutlich besser als ??? Es wird gekränkelt.

2 Mit heftig ergibt z. B. der Test für ähneln ein negatives Ergebnis (*Sie ähnelt ihm heftig), mit gewaltig fällt das Ergebnis wieder positiv aus. 
(9) a. Die Stadtwerke reißen das Gebäude ab.

b. Das Gebäude wird gerade abgerissen.

c. Das Gebäude ist bereits abgerissen.

Die kursiv hervorgehobene Nominalgruppe in (9)(a) bezeichnet einen Partizipanten, der einer Zustandsänderung unterliegt und damit nach der in Abschn. 3.2 genauer betrachteten Definition als "Patiens“ klassifiziert werden müsste. Dieselbe thematische Rolle käme der NG in der Subjektposition der entsprechenden Passivkonstruktion, Beispiel (9)(b), zu. Problematisch ist nun die Resultativkonstruktion (traditionell „Zustandspassiv“) in (9)(c). Resultativkonstruktionen drücken einen Zustand aus, der die Folge einer vorausgegangenen Handlung oder eines vorausgegangenen Vorgangs ist (Nedjalkov und Jachontov 1988: 6). Damit muss die kursiv markierte NG in (9)(c) nach der in diesem Abschnitt erörterten Definition als „Zustandsträger" (Ferens) klassifiziert werden. Das Problem für ein derivationell organisiertes Valenzlexikon besteht nun darin, dass es eine solche Rollenzuweisung unmöglich macht, die ValenzRealisierungsstrukturen in (9)(a)/(b) und in (9)(c) aufeinander zu beziehen: Wenn das Gebäude in (9)(a)/(b) Patiens ist, das Gebäude in (9)(c) aber Ferens, dann kann es sich nicht um Realisierungsstrukturen desselben Aktanten handeln. Andererseits ist es für ein solches Valenzlexikon praktisch unumgänglich, den Bezug zwischen (9)(a)/(b) und (9)(c) herzustellen, da über den derivationellen Zusammenhang abreißen $\rightarrow$ abgerissen (wie immer man ihn grammatiktheoretisch einordnen möchte) kein Zweifel bestehen kann. Die Aufnahme der statischen Rolle „Ferens“ in unser Rollenrepertoire bringt uns also in eine Zwickmühle, aus der es ohne erheblichen grammatiktheoretischen Aufwand (etwa durch die Verwendung von intern komplexen Rollen, Transformationsregeln oder semantischen Dekompositionsstrukturen) keinen Ausweg gibt. Auf der anderen Seite stellt sich das beschriebene Problem erst gar nicht, wenn man nicht zwischen dynamischen und statischen Rollen unterscheidet und die NG das Gebäude in (9) einheitlich als „Patiens“ klassifiziert (vgl. Fillmore 2003: 467, für einen Vergleich beider Ansätze).

Im Moment sehen wir keine andere Möglichkeit, als die theoretische Inkonsistenz im Hinblick auf die rein deskriptive Zielsetzung unseres Valenzlexikons in Kauf zu nehmen und bei der Zuordnung der Realisierungsstrukturen in (9) implizit von einer Rollenneutralisierung "Patiens $>$ Ferens" im Kontext von Resultativkonstruktionen und gewissen Nominalisierungen (z. B. nach dem Abriss des Gebäudes) auszugehen. Die eindeutige Zuordnung der Realisierungsstrukturen ist dann zumindest durch die Position im Aktantenrahmen (in allen Fällen handelt es sich um A-2) gewährleistet. 


\subsection{Agens, Kausator und Instrumental}

Wir verlassen damit die Frage der dynamischen und statischen Partizipanten und wenden uns der Frage zu, ob man belebte Agentien von unbelebten Kausatoren unterscheiden muss. Mit „Kausator“ (CAUS) ${ }^{1}$ oder ähnlichen Rollen operieren z. B. Grepl und Karlík (1983), die [PMČ] (Karlík, Pleskalová und Nekula 1995: 384), Levin und Rappaport Hovav (1995: 83 f.), Helbig und Buscha (1999: 635), Reinhart (2002), Reinhart und Siloni (2005), Haiden (2005: 41) und neuerdings auch Alexiadou und Schäfer (2006) sowie Martin und Schäfer (2014). Selbstverständlich gibt es dabei zwischen den einzelnen Konzeptionen auch erhebliche Unterschiede, die wir hier aus Platzgründen vernachlässigen müssen. Fillmore (1968) subsumierte die Rolle ursprünglich unter „Instrumental“, führt später aber eine gesonderte Rolle „Naturkraft“ („force“) $)^{2}$ ein (vgl. z. B. auch Van Valin und LaPolla 1997: 85). Die Grundidee hinter der Rolle „Kausator“ ist die Beobachtung, dass es Partizipanten gibt, die ein Ereignis verursachen, ohne dabei willentlich eine Handlung auszuführen. Ein typisches Beispiel wäre etwa der Sturm in Der Sturm hat die Dächer abgedeckt: Wenn man Agens an das Merkmal „willentlich“ bindet, braucht man für solche Fälle eine neue Rolle. Tut man dies dagegen nicht, wie wir gerade im ersten Abschnitt dieses Kapitels entschieden haben, dann scheint auch die Kausator-Rolle überflüssig zu werden. Ist dies aber tatsächlich so? Betrachten wir zur näheren Klärung der Verhältnisse zwei Gruppen von (konstruierten) Beispielen:

(10) a. Peter / Die Strömung / Der Aufprall hat die Blechvorrichtung verbogen.

b. Die Blechvorrichtung hat sich verbogen. ${ }^{3}$

(11) a. Peter $/{ }^{*}$ Die Brandung $/{ }^{*}$ Die Creme hat Claudia eingekremt.

b. Claudia hat sich eingecremt.

In beiden Beispielgruppen würde man wohl die durch Strömung, Aufprall, Brandung oder Creme realisierte SubE, gestützt auf das Merkmal [-anim], als „Kausator“ bezeichnen, die SubE, die durch den Eigennamen mit dem Merkmal [+hum] realisiert wird, dagegen als „Agens“. Die Beispiele in (a) zeigen nun, dass bei einer

1 Laut Alexiadou und Schäfer (2006, Fußnote 1) geht das Konzept auf Gruber zurück, dessen Arbeit uns aber leider nicht zur Verfügung stand. Die Rollenbezeichnung „Kausator“, die wir hier verwenden, ist eine eingedeutschte Version der tschechischen Bezeichnung, die Grepl und Karlík (1983; 1998) geprägt haben.

2 Wir benutzen „force“ weiter unten im Text (und in unserem Valenzlexikon) nicht als Rollenlabel, sondern als sortales Merkmal auf derselben Ebene wie etwa [+hum], um bestimmte, grammatisch relevante Eigenschaften von Referenten sprachlicher Ausdrücke zu erfassen.

3 Ein authentischer Beleg für die kausative Verwendung mit unbelebtem Kausator, der in unserer Zufallsstichprobe zur Erstellung des Eintrags für verbieGEN enthalten ist, lautet z. B.: Die Strömung war stärker als erwartet und hatte die Aluminiumrotorblätter verbogen [DeReKo]. Für die reflexive, dekausative Verwendung ließe sich folgender Korpusbeleg zitieren: Vorn am ICE sind Schneeschieber ständig angebaut, diese hatten sich verbogen [DeReKo]. 
völligen Neutralisierung der Rollenunterschiede zwischen Agentien und Kausatoren bestimmte, grammatisch relevante Unterschiede nicht mehr erfasst werden können. Während in (10)(a) die Position des Erstaktanten durch Ausdrücke besetzt werden kann, die Menschen, Naturkräfte und Vorgänge bezeichnen, ist in (11)(a) nur die Besetzung durch Ausdrücke, die Menschen bezeichnen, möglich. Die Beispiele in (b) zeigen zudem, dass diese Eigenschaft der beiden Valenzträger verbiegen und eincremen offenbar mit einer weiteren Eigenschaft korreliert: Nur im ersten Fall führt die Reflexivierung zu einer Konstruktion, die zur Beschreibung eines unwillkürlichen Vorganges an einem unbelebten Gegenstand verwendet werden kann. Im zweiten Fall wird die Konstruktion semantisch reflexiv interpretiert, d. h. so, dass ein gezielt handelnder, im Normalfall „menschlicher“ Partizipant eine Handlung an sich selbst ausführt.

Konstruktionen wie die in (10)(b) werden bei Grepl und Karlík (1983: 71 f.) auf eine syntaktische Transformation („Dekausativierung“) zurückgeführt, die aus der Subjektposition der Basisstruktur eine Konstituente mit dem Merkmal [+cause], nicht aber eine Konstituente mit dem Merkmal [+agent] entfernen kann (vgl. den sehr ähnlichen Ansatz bei Reinhart 2002 und dessen Anwendung auf das Deutsche bei Haiden 2005). Will man, ganz unabhängig von den technischen Details bei Grepl und Karlík, die Bildbarkeit von Konstruktionen wie (10)(b) erfassen, so müssen sich die entsprechenden Merkmale in irgendeiner Form im Aktantenrahmen widerspiegeln. Die Verwendung der sortalen Merkmale [+hum] und [-hum] ist dafür allerdings nicht ausreichend: Durch das Merkmal [+hum] ließe sich zwar die Beschränkung bei der Besetzung von SubE ausdrücken, die in Beispiel (11) (a) zu erkennen ist; andererseits ist es aber nicht möglich, die Anwendung der Dekausativierungsregel in (10)(b) vom Vorliegen des Merkmals [-hum] abhängig zu machen. Das Verb verbiegen ist ja, wie (10)(a) zeigt, problemlos mit belebten Subjektaktanten konstruierbar und darf der SubE daher gerade nicht das Merkmal [-hum] zuweisen.

Aus dem bisher Gesagtem schließen wir, dass (a) einerseits eine Unterscheidung zwischen Agens und Kausator notwendig ist (um Dekausativierung und Einschränkungen bei der Positionsbesetzung von A-1 erklären zu können), dass aber (b) andererseits (sowohl aus theoretischen als auch aus empirischen Gründen) eine Gleichsetzung von belebtem A-1 mit Agens und von unbelebtem A-1 mit Kausator nicht in Frage kommt.

Der Unterschied zwischen Agentien und Kausatoren, der in (10) und (11) deutlich wird, lässt sich aber auch anders fassen als durch die sortalen Merkmale der Ausdrücke, die die entsprechende Valenzposition besetzen ([ \pm hum]). In Arbeiten wie Hale und Keyser (1993), Haspelmath (1993), Levin und Rappaport Hovav (1995), Van Valin und LaPolla (1997) oder Kaufmann (2004) wird darauf hingewiesen, dass die lexikalische Information bei verschiedenen Verben unterschiedlich auf die einzelnen Teile der semantischen Dekompositionsstruktur verteilt sein kann. Es 
gibt Verben, die genaue Informationen zur Aktivität des Erstaktanten enthalten, und andere Verben, die zwar die Aktivität eines Erstaktanten voraussetzen, in ihrer lexikalischen Struktur aber lediglich Informationen zu der durch diese Aktivität verursachten Wirkung enthalten. So spezifiziert etwa das Verb öffnen zwar Informationen zum erreichten Endzustand des benannten Sachverhaltes (,etwas ist offen'), lässt dabei aber gleichzeitig offen, durch welche Einwirkung dieser Endzustand erreicht wird. Dasselbe ließe sich von dem Verb verbiegen in (10)(a) sagen: Der Endzustand des durch den Zweitaktanten bezeichneten Gegenstandes ergibt sich mit zwingender Notwendigkeit aus der lexikalischen Bedeutung des Valenzträgers (,etwas ist verbogen'), nicht dagegen die Art der Aktivität von A-1, die zu diesem Endzustand geführt hat. Kaufmann (2004: 63) setzt in solchen Fällen daher für die semantische Struktur des Valenzträgers ein unspezifisches Aktivitätsprädikat und ein spezifisches Zustandsänderungsprädikat an.

Bei eincremen in (11)(a) liegen die Dinge dagegen umgekehrt. Das Verb vermittelt recht spezifische Informationen zur Art der Aktivität, die den Endzustand des benannten Sachverhaltes (im Beispiel ,jemand ist eingecremt') herbeiführt. Zum Beispiel muss diese Aktivität unter Verwendung einer bestimmten Substanz ausgeführt werden, erkennbar an der Wortbildungsstruktur des Verbs, sowie einer spezifischen Art der Verarbeitung dieser Substanz entsprechen (,mit Händen auf eine Fläche auftragen'; würde die Creme durch eine Düse auf eine Fläche gespritzt, könnte man nicht von, eincremen' sprechen).

Die spezifischen Informationen in der Verbsemantik zur verursachenden Aktivität stellen ebensolche spezifischen Anforderungen an die Sorte des Partizipanten, der in der entsprechenden Valenzposition benannt wird. Im Falle von eincremen muss dieser Partizipant z. B. mit Händen ausgestattet sein und über die notwendige Feinmotorik verfügen, um die vom Verb spezifizierte Aktivität ausführen zu können. Das schließt Partizipanten wie Brandung oder Creme als mögliche Kandidaten von vorne herein aus. Umgekehrt stellen Verben, die keine oder nur sehr allgemeine Informationen zur verursachenden Aktivität vermitteln, nur sehr vage Forderungen an die Partizipanten, die in der entsprechenden Valenzposition spezifiziert werden sollen. Im Falle von verbiegen in (10)(a) reicht es aus, wenn dieser Partizipant genügend Eigenaktivität entwickelt, um die Zustandsänderung beim zweiten Partizipanten herbeizuführen. Diese Forderung lässt sich durch eine ganze Reihe von unterschiedlichen Partizipanten mit einer breiten Palette von sortalen Merkmalen wie [+hum], [+force] oder [+akt] erfüllen, wie dies auch aus (10)(a) ersichtlich ist.

Es liegt nun nahe, den Unterschied zwischen „Agens“ und „Kausator“ eben an diesen Unterschied in der semantischen Struktur der Valenzträger zu knüpfen und „Kausator" als denjenigen Partizipanten zu definieren, der durch eine unspezifische, d. h. in der Bedeutung des zugehörigen Valenzträgers nicht spezifizierte Eigenaktivität eine Zustandsänderung bei einem weiteren Partizipanten bewirkt. Beschränkungen 
bei den sortalen Merkmalen und Dekausativierbarkeit ${ }^{1}$ sind dann die Folge der unterschiedlichen Rollenverteilung, nicht deren Voraussetzung. Es muss allerdings darauf hingewiesen werden, dass sich aus diesem Ansatz eine ungewöhnliche Situation ergibt: Da das Verb verbiegen seinem A-1 die unspezifische KausatorRolle zuweist, muss Peter in (10)(a) - trotz des Merkmals [+hum] - als Kausator betrachtet werden, und dies zunächst auch dann, wenn er die Blechvorrichtung mit voller Absicht und zielgerichtet verbogen hat. Wir verweisen eine agentive Uminterpretation der Struktur mit anderen Worten in den Bereich der Pragmatik und müssen dabei in Kauf nehmen, dass unser Beschreibungssystem in diesem Punkt von der sonst gängigen Praxis abweicht.

Am Ende bleibt noch die Frage, ob außer „Agens“ und „Kausator" noch weitere dynamische Rollen, insbes. die Rolle „Instrumental“ notwendig sind, um die Position des Erstaktanten erschöpfend zu charakterisieren. Hier teilen wir die Ansicht von Alexiadou und Schäfer (2006), dass das, was gewöhnlich als „Instrument in Subjekt-Position“ bezeichnet wird, zumindest im Deutschen unter die Agens- oder Kausator-Rolle fällt. Wenn eine metonymische oder metaphorische Umdeutung der Partizipanten in der A-1-Position als Agens oder Kausator nicht möglich ist, scheinen uns (genau wie Alexiadou und Schäfer) die entsprechenden Strukturen im Deutschen sowieso eher fragwürdig zu sein:

(12) a. 'Der Schlüssel öffnet die Tür. [Alexiadou und Schäfer 2006, Bsp. 36a, inkl. Bewertung]

b. 'Der Stift schreibt einen Brief.

Wie Alexiadou und Schäfer (2006) wohl korrekt anmerken, werden Sätze wie (12) (a) nur bei Austausch des Determinativs und/oder kontrastiver Betonung akzeptabel (Dieser Schliussel öffnet dir jede Tür). Die Emphase hebt eine spezifische Eigenschaft des Referenten von A-1 hervor, die für das Zustandekommen der Situation verantwortlich ist. Damit rückt die Konstruktion in die Nähe des sog. MedioPassivs (Dieses Buch liest sich leicht, vgl. z. B. Fagan 1992); das Prädikat wird statisch, vgl. (13), und A-1 wäre nach unserem System somit als „Ferens“ zu kennzeichnen.

*Dieser Schlüssel öffnet gerade die Tür.

1 An dieser Stelle soll allerdings nicht behauptet werden, dass der Zusammenhang zwischen A-1 (=Kausator) und Dekausativierbarkeit wirklich so eng ist, dass er für eine vollständige Erklärung der Datenlage ausreicht. Es gibt Hinweise, dass dem nicht so ist, vgl. etwa Peter / der Aufprall hat das Glas beschädigt $\times{ }^{*}$ Das Glas hat sich beschädigt. Für unsere Zwecke ist aber entscheidend, dass die Fälle mit A-1 (=Kausator) im Lexikon dokumentiert werden, da dies die Voraussetzung für die Überprüfung der grammatischen Regeln ist. Dafür müssen „Agens“ und „Kausator“ natürlich zunächst einmal durch die Notation unterschieden werden und dürfen nicht in einer einzigen Proto-Agens-Rolle zusammenfallen. 
In dieselbe Richtung weisen auch die Korpus-Daten, die wir für die Besetzung der A-1-Position von schreiben mit unbelebten Aktanten ermittelt haben:

(14) Die Trichterfeder schreibt nur gut, wenn sie senkrecht gehalten wird. [DeReKo]

(15) a. [...] denn das Kleingedruckte in den Zeitungen schreibt immer deutlich, dass es „trocken“ zuging. [DeReKo]

b. Ich bin überzeugt, dass der Euro die gleiche Erfolgsstory schreibt wie die Deutsche Mark. [DeReKo]

Die Sätze geben entweder wie (14) eine Eigenschaft des Partizipanten in der Subjektposition an, der demgemäß als „Ferens“ zu klassifizieren ist, oder gehen auf metonymischen, (15)(a), bzw. metaphorischen, (15)(b), Gebrauch zurück, womit nach Alexiadou und Schäfer (2006) der Erstaktant das (metaphorisch verstandene) Agens der beschriebenen Situation ist. Uns erscheint daher die Rolle „Instrumental“ im A-1-Bereich entbehrlich zu sein. Notwendig ist sie vermutlich nur zur Notierung der Verhältnisse in Valenz-Erweiterungspositionen, ${ }^{1}$ wobei allerdings fraglich ist, ob solche Erweiterungspositionen überhaupt dokumentiert werden müssen, da die Möglichkeit ihres Auftretens beim Vorliegen bestimmter Voraussetzung vollständig prädiktabel ist (vgl. Welke 2015: 51-53).

\subsection{Experiencer und Stimulus}

Das letzte Rollenpaar, das wir in diesem Abschnitt noch betrachten wollen, ist das Rollenpaar „Experiencer" und "Stimulus“. Auch hier treffen Engel (2009) bzw. [BKS] keine Rollenunterscheidung gegenüber den sonstigen Nom-Akk-Verben. Der Erstaktant bei typischen Experiencer-Stimulus-Verben ${ }^{2}$ wie bemerken, beobachten, finden, fürchten, glauben, lieben, merken, riechen, sehen, verachten, oder vergessen ${ }^{3}$ wird - genau wie der Erstaktant von typischen Nom-Akk-Verben wie bauen - als AGT““ gefasst. Auch der Erstaktant von Stimulus-Experiencer- oder (in der Terminologie von Möller 2007) psychischen Wirkungsverben wird in [BKS] gegenüber dem Erstaktanten von Agens-Patiens-Verben nicht speziell ausgezeichnet. Verben wie ärgern, aufregen, einschüchtern, enttüuschen, erinnern, interessieren oder überraschen

1 Zu Valenz-Erweiterungspositionen, vgl. z. B. Welke (1988, Kap. 3.2; 2011, Kap. 12) oder Ágel und Fischer (2010: 270).

2 Wir wollen mit der Aufzählung oben nicht behaupten, dass die angeführten Verben eine homogene Klasse bilden. Zum Beispiel scheint beobachten agentiver zu sein als sehen; bemerken ist ein punktuelles Verb, beobachten und sehen sind dagegen durativ.

3 Der A-1 bei vergessen erhält bei Djordjević und Engel [BKS, S. 600] das Subskript mut; alle anderen Erstaktanten der Verben in der Aufzählung oben sind dagegen mit fer subskribiert. Vermutlich ist das Subskript mut entweder ein Fehler oder auf rein intuitive Erwägungen zurückzuführen, da sich der Erstaktant dieses Verbs gerade nicht wie ein typisches Patiens, das einer Zustandsäderung unterliegt, verhält, vgl. Ich bin erkältet (,ich habe eine Erkältung') $\times{ }^{*} I c h$ bin vergessen (in der Bedeutung, ich weiß etwas nicht mehr'). 
implizieren einheitlich $\mathrm{AGT}_{\mathrm{fer}}$ (mit „verminderter Agentivität“ bei interessieren und überraschen ${ }^{1}$ ).

Nun weisen aber Valenzträger, die in ihrem Aktantenrahmen einen „Experiencer“ oder "Wahrnehmungsträger“ (Helbig und Buscha 1999: 561) enthalten, grammatische Besonderheiten auf, die seit geraumer Zeit in der Fachliteratur diskutiert werden (vgl. z. B. Belletti und Rizzi 1988; Grimshaw 1990; Sonntag 2004; Kailuweit 2005; Möller 2007; Vázquez 2011). Betrachtet man die Verteilung der Rollen auf die Positionen im Aktantenrahmen, dann ist die auffälligste Erscheinung, dass die beiden Rollen „Experiencer" und „Stimulus“ keiner eindeutigen RollenHierarchie folgen (vgl. z. B. Grimshaw 1990: 8; Möller 2007: 12). Bei manchen Valenzträgern wird der Stimulus in der höheren Position aktantisiert, (16)(a), bei anderen in der niedrigeren Position, wobei der Experiencer dann in der höheren Position erscheint, (16)(b).

(16) a. Du erstaunst mich.

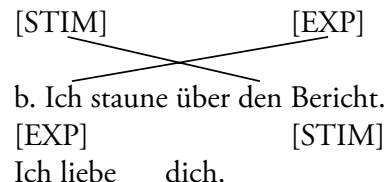

Ein solches Schwanken in der Hierarchisierung ist bei Agens-Patiens-Verben völlig unbekannt.

Mit dieser Besonderheit beim Linking gehen weitere Spezifika der entsprechenden Valenzträger einher. So bilden viele ${ }^{2}$ Verben der Gruppe reflexive Konversen, (17), blockieren, sofern der Experiencer in der niedrigeren Position aktantisiert ist, die Infinitivnominalisierung, (18), und die Passivierung, (19), und erlauben die prädikative Verwendung von Partizip 1, die bei den meisten anderen Verben kaum möglich ist, (20):

(17) a. Das hat mich aufgeregt.

b. Darüber brauchst du dich nicht aufregen.

(18) *Die Dozenten streben ein intensives Interessieren der Mädchen an. [Blume 2004: 68, Bsp. 4]

(19) *Sie wird interessiert. *Ich wurde gefreut.

(20) Diese Sache ist beeindruckend. $\times$ *Das Kind ist lesend. [Möller 2007: 16, Bsp. 38]

1 Bei überraschen [BKS, S. 574] werden zwei Rahmen angesetzt: überraschen1 (AGT'fer - AFFmut) wie in Deine Gelassenheit überrascht mich und überraschen2 (AGT “ - AFFfer - LOC) wie in Gestern habe ich Daniela beim Rauchen überrascht. Die „verminderte Agentivität“ betrifft nur die erste Variante.

2 In anderen Fällen fehlen solche Konversen dagegen: Du erstaunst mich $\times{ }^{*} I$ Ich habe mich erstaunt. Dieser Umstand ist erklärungsbedürftig und erfordert eine ausgedehntere Dokumentierung entsprechenden Sprachmaterials. 
Für den deutsch-tschechischen Sprachvergleich ist daneben wichtig, dass es sprachspezifische Beschränkungen bei der Besetzung von Stimulus-Positionen gibt, die sich im Deutschen und Tschechischen nicht zu decken brauchen. So weist etwa Štícha (2003: 521) darauf hin, dass die Subjektposition des direkten deutschen Äquivalents für těsit ,freuen' nicht - wie im Tschechischen - durch Bezeichnungen für personale Partizipanten besetzt werden kann, und dies, obwohl die Äquivalente in beiden Sprachen ansonsten dieselbe Konversenbildung zeigen:

(21) a. Teším se z toho. / To mě těší. / Těsil jsem ji. [Štícha 2003: 521]

b. Ich freue mich darüber. / Das freut mich. / ${ }^{*}$ Ich freute sie. ${ }^{1}$

Alle genannten Erscheinungen sind für ein derivationell und kontrastiv organisiertes Valenzlexikon hoch relevant und müssten systematisch dokumentiert werden. Die Voraussetzung dafür ist natürlich, dass die entsprechenden Valenzträger identifiziert werden können, und dies ist ohne die Verwendung der komplementären Rollenlabels „Experiencer“ und „Stimulus“ wohl kaum möglich.

Hiermit schließen wir den Überblick über die in der Position des Erstaktanten benötigten Rollen ab und wenden uns den Rollen zu, die (zumindest vorwiegend) im Bereich des Zweitaktanten angesiedelt sind.

\section{Rollen im Bereich des Zweitaktanten}

Engel (1991: 360) unterscheidet im unteren Bereich des Aktantenrahmens die Rollen EFF (effizierter Partizipant), OBJ (Objekt) und PAT (Patiens), die alle in einer Abhängigkeitsrelation zu AG (Agens) stehen: Sie sind durch das vom Agens ausgehende Geschehen im weitesten Sinne betroffen. Im Folgenden werden der Reihe nach die Engel'schen Definitionen und Beispielsätze angeführt und bei Zweifelsfällen auch kommentiert.

\subsection{Effizient und Affizient}

EFF ist das Symbol für „neu Geschaffenes oder Entstandenes“. Diese knappe Definition (vgl. Engel 1991: 360) wird anhand folgender Beispiele illustriert (die Seitenzahlen beziehen sich auf Engel [1991], die Realisierungsstruktur der jeweils zur Diskussion stehenden Rolle ist durch Kursivdruck hervorgehoben):

(22) a. Michael schnitt den Braten in dünne Scheiben. [S. 371]

b. Paul teilte den Kuchen in zwölf gleiche Stücke. [S. 373]

1 Die Kausativ-Konstruktion erfordert im Deutschen die zusätzliche Realisierung des Präfixes er(Ich erfreue sie mit einem Geschenk). Ähnlich liegen die Verhältnisse übrigens auch bei wundern: Ich wundere mich. I Das wundert mich. I *Sie wundert mich. Es wäre wünschenswert, weitere Fälle zu identifizieren. 
c. Die beiden Flüssigkeiten verbinden sich (miteinander) zu einer dunkelbraunen Masse. [S. 375]

Es ist allerdings in den o. g. Fällen einzuwenden, dass die als EFF interpretierten Präpositionalgruppen, im Gegensatz zu akkusativischen Nominalgruppen in Sätzen wie Opa schrieb einen Roman, eigentlich nichts neu Entstandenes bezeichnen, sondern eher eine neue Erscheinungsform des bereits in der Akkusativposition spezifizierten Patiens darstellen. Geht man von der Vorstellung aus, dass thematische Rollen bestimmten Partizipanten einer durch den VT benannten Situation beigelegt werden, dann ließe sich die Ansicht vertreten, dass die Präpositionalgruppen in (22) überhaupt keine thematischen Rollen tragen. Sie bezeichnen nämlich keinen selbständigen Partizipanten der Situation, sondern eine neue Eigenschaft oder Zustandsform des zweiten Partizipanten und stellen demnach sekundäre Prädikationen zur Hauptprädikation dar (,Der Braten besteht aus Scheiben', ,Der Kuchen besteht aus zwölf Stücken', ,Die Flüssigkeit ist eine dunkelbraune Masse'). Besonders deutlich ist dies im ersten Beispiel zu sehen, wo in dünne Scheiben durch ein Adjektiv ersetzt werden kann:

(23) Michael schnitt den Braten klein.

Wir gehen nicht davon aus, dass prädikative Elemente Rollen tragen, und schließen die PGs in (22) daher von der Klassifizierung aus. Aus demselben Grund nehmen wir auch nicht an, dass der „Klassifikativ“, der bei Engel (2009: 191) auf derselben Stufe wie „Agentiv“ und „Affektiv“ angesetzt wird, als thematische Rolle zu betrachten ist. Damit soll natürlich nicht gesagt sein, dass dieses Konzept nicht vielleicht für andere Zwecke, z. B. für die vollständige semantische Charakterisierung aller Satzglieder, brauchbar wäre.

Es bleibt die Frage, ob man die Rolle EFF für ,effiziertes Objekt' zur Abgrenzung von lediglich affizierten Objekten benötigt. Engel behält das Label (in Form des Subskripts eff an der Proto-Patiens-Rolle AFF) auch in seinem innovierten System von 2004 bei (vgl. Engel 2009: 192). Auch Fillmore (1968) war der Meinung, dass der Unterschied zwischen affiziertem und effiziertem Objekt, zumindest im Englischen, grammatisch relevant ist. Ob dies auch für das Deutsche gilt, ist uns im Moment nicht klar. ${ }^{1}$ Auf den ersten Blick könnte sich ein Kontrast bei der Alternation $\mathrm{NG}_{\mathrm{Akk}} / \mathrm{PG}_{a n}$ ergeben, die vorwiegend effizierte, nicht affizierte A-2 zu

1 Das Beispiel, das Fillmore anführt, bezieht sich auf die Bildung von Fragen bei gleichzeitiger Überführung von A-2 in eine PG mit to, was nur bei affizierten, nicht bei effizierten Objekten möglich ist (John ruined the table $\rightarrow$ What did John do to the table? $\times$ John built the table $-/ / \rightarrow$ What did John do to the table?). Wenn man versucht, den Kontrast im Deutschen zu reproduzieren (Was hat John mit dem Tisch gemacht?), ist der entstehende Kontrast u. E. nicht besonders deutlich. 
betreffen scheint, vgl. folgende Varianten von Lexemen, deren Basis-Variante laut [BKS] die Rolle $\mathrm{AFF}_{\text {eff }}$ impliziert: $^{1}$

(24) a. Klaus schreibt an einem Roman. [BKS, S. 502]

b. Sie bauen immer noch an ihrem Haus. [BKS, S. 113]

Allerdings lassen sich auch bei Valenzträgern mit affiziertem Objekt (im System von Engel 2009 als $\mathrm{AFF}_{\text {mut }}$ notiert) Alternationen konstruieren, wobei jedoch zuzugestehen ist, dass (zumindest im Beispiel unten) die zusätzliche Realisierung eines spezifischen Präfixes (herum) notwendig wird:

(25) a. Er repariert den Wagen. [BKS, S. 469, mit $\left.\mathrm{AFF}_{\text {mut }}\right]$

b. Er repariert immer noch an seinem Wagen herum. [konstruiert]

Auch bei Nominalisierungen, die ja für ein derivationell organisiertes Valenzlexikon besonders wichtig sind, zeichnet sich kein Unterschied zwischen EFF bzw. AFF ${ }_{\text {eff }}$ auf der einen, und OBJ bzw. FFF $_{\text {mut }}$ aufder anderen Seite ab: In beiden Fällen kann der A-2 in adnominaler Genitiv-Position realisiert werden:

(26) a. das Schreiben eines Romans [konstruiert]

b. das Reparieren des Wagens [konstruiert]

Diese Feststellung bestätigen auch die Ergebnisse von Vázquez (2011: 184-187), die die Realisierung der beiden Rollen im Kontext von Verbalsubstantiven untersucht. Die dominierende adnominale Position ist sowohl für $\mathrm{AFF}_{\text {eff }}$ als auch für $\mathrm{AFF}_{\text {mut }}$ (bei Vázquez kurz EFF und MUT) der Genitiv bzw. die PG von + Dativ. Auch die zusätzliche Unterscheidung bei EFF zwischen ,Erschaffung' und ,Vernichtung“ (Veröffentlichung des Berichts vs. Auflösung des Agrarministeriums, Vázquez 2011:183) korreliert offenbar nicht systematisch mit formalen Unterschieden bei der Kodierung der Rolle. Wir sehen daher von einer feineren Differenzierung ab und fassen die Rolle einheitlich als „Patiens“, d. h. als Rolle desjenigen Partizipanten, der einer Zustandsveränderung (einschließlich von Entstehen oder Verschwinden) unterliegt (vgl. Fillmore 2003: 464).

\subsection{Patiens, Objektiv und Rezipient}

Der Rolle „Patiens“ im oben verstandenen Sinne entspricht bei Engel am ehesten die Rolle OBJ, vom Autor als „nicht willkürlich reaktionsfähiges Objekt eines Geschehens" definiert (Engel 1991: 360). Wegen der großen Menge an Beispielen (Engel 1991: 362-377) führen wir nur einige wenige, repräsentative Belege an:

1 Eine Inkonsequenz scheint uns zu sein, dass die PGan der Alternante im Wörterbuch unterschiedlich beurteilt wird: bei schreiben als AFFeff, bei bauen dagegen als AFFmut. 
(27) a. Uli brachte dem Vater den Koffer ins Büro. [S. 365]

b. Sie öffnete den Safe mit einem Zweitschlüssel. [S. 369]

c. Er trank nur Milch. [S. 374]

d. Wir haben die Landschaft total verändert. [S. 374]

e. Ich sage ihnen die Wabrheit. [S. 371]

f. Inge hört auf mit ihren Beschwerden. [S. 363]

g. Es drehte sich um meine Mutter. [S. 365]

h. Ich habe mit Meiers über ihren Urlaub geredet. [S. 370]

i. Jetzt gilt es zu sparen. [S. 366]

j. Du solltest beachten, dass er drei Jahre in Mexiko war. [S. 364]

Als typische Ausdrucksform tritt eine NG im Akkusativ auf, (27)(a)-(e). Daneben sind verschiedene PGs, (27)(f)-(h), Infinitive mit $z u$, (27)(i), und eingebettete Nebensätze, (27)(j), mögliche Realisierungsformen von OBJ. Ob ein Infinitiv mit $z u$ wie in (27)(i) oder ein Nebensatz wie in (27)(j) wirklich als „nicht willkürlich reaktionsfähiges Objekt eines Geschehens“ zu verstehen ist, kann wohl als fragwürdig gelten. Wenn wir uns in anderen Quellen umsehen, die sich mit Nebensätzen und Infinitiven in der Rolle von Partizipanten befassen, finden wir mancherorts eine prinzipielle Unterscheidung zwischen substantiellen und situativen Partizipanten, so z. B. in [PMČ, S. 384 f.]. Situative Partizipanten werden nach [PMČ, S. 386] primär durch Sätze ausgedrückt, die auf syntaktischer Ebene (ähnlich wie bei Engel) die Gültigkeit eines Objektsatzes haben. Auf semantischer Ebene wird den situativen Partizipanten die Rollen „Information“ bzw. „Instruktion“ zugesprochen, z. B. in V rádiu hlásili, že bude pršet ,Im Radio meldete man, dass es regnen wird', Je nařizeno, abychom se prezouvali ,Es ist angeordnet, die Schuhe zu wechseln" [PMČ, S. 386]. Würde man wie Engel auch satzförmigen Ergänzungen die primär für NGs gedachten Rollen zuweisen wollen, müsste man übrigens den Nebensatz in Beispiel (27)(j) nicht als „Objekt“, sondern als „Stimulus“ klassifizieren, da die Subjektergänzung des Verbs beachten ja ein „Wahrnehmungsträger“ (Experiencer) ist. Der Nebensatz drückt den Inhalt aus, der zu beachten ist.

Das von Engel angeführte Beispiel (27)(i) für einen Infinitiv mit $z u$, der die Rolle „Objektiv“ trägt, wird an anderen Stellen derselben Grammatik neutral (nach formalsyntaktischen Kriterien) als „Verbativergänzung“ (Engel 1991: 198) charakterisiert, ohne dabei auf die rollensemantische Einordnung zurückzukommen. Uns scheint dies die günstigste Lösung zu sein: Satzförmige oder infinitivförmige Ergänzungen können einer Position im Aktantenrahmen (A-1, A-2, PER etc.) zugeordnet werden, ohne unbedingt eine thematische Rolle zu erhalten.

Kehren wir nun zu den Rollen für substantielle Partizipanten bei Engel zurück. Das Rollen-Label PAT wird bei Engel nicht gemäß dem sonst üblichen Usus verwendet und verdient daher besondere Aufmerksamkeit. Laut Engel (1991: 360) ist ein „Patiens“ ein „Opfer, Erleidender“ und „kann willkürlich reagieren (meist Menschen)." Engel führt u. a. folgende Beispiele an: 
(28) a. Sabine zieht ibre Kinder an. [S. 363]

b. Ich rufe den Hund. [S. 366]

c. Ich habe ihn zu einem neuen Wohnzimmer überredet. [S. 374]

d. Jetzt habe ich dir alles erzählt. [S. 365]

e. Schenk mir einen bunten Luftballon. [S. 371]

f. Er sagte nichts zu ihrer Schwester. [S. 371]

g. Vater hat den Kuchen an seine Kinder verteilt. [S. 376]

h. Hugo hat von mir eine Unterschrift verlangt. [S. 375]

Vermutlich geht die eigentümliche Belebtheitsforderung für „Patiens“ auf die Rezeption der Rolle „Dativ“ zurück, die Fillmore (1968) explizit auf belebte Partizipanten einschränkt und als „case of the animate being effected by the state or action identified by the verb" (Fillmore 1968: 24) definiert. ${ }^{1}$ Wir diskutieren die Rollenzuweisung von Engel entsprechend der Formmerkmale der Realisierungsstrukturen, wie sie aus den Beispielsätzen ersichtlich sind.

Die Beispiele (28)(a)-(c) zeigen die für ein Patiens (im üblichen Sinne) erwartete Realisierung durch eine NG im Akkusativ. Aus formaler Sicht überschneidet sich hier die Realisierungsstruktur von PAT (im Sinne von Engel) mit OBJ. In diesem Zusammenhang ist der Frage nachzugehen, ob die inhaltliche Seite, d. h. die unterschiedlichen Definitionen der Rollen, ein relevantes Unterscheidungskriterium darstellt. $^{2}$ Die Tatsache, dass ein Partizipant in einer tieferen Position des Aktantenrahmens „reaktionsfähig“ ist, könnte ja tatsächlich Auswirkungen auf die formale Kodierung habe. So grenzt etwa auch Blume (2000) eine Gruppe von Verben mit markiertem Linking-Muster ab, bei denen der Zweitaktant gewisse Proto-Agens-Eigenschaften hat. Laut Blume führt dies zu verminderter Transitivität, die sich dann in einer vom Normalfall abweichenden Wahl des Formmerkmals für die A-2-Realisierung (z. B: Dativ wie in jemandem folgen) niederschlagen kann.

Betrachten wir unter diesem Gesichtspunkt noch einmal genauer den A-2 in (28)(a). Es ist wohl bekannt, dass anziehen zu den Verben mit alternierenden Aktantenrahmen gehört (vgl. z. B. Bierwisch 1996: 363). Wir illustrieren die Situation mit authentischen Korpus-Belegen aus DeReKo (die Aktanten-Position, die Engel als „Patiens“ betrachten würde, ist kursiv hervorgehoben):

(29) a. Wir wollten ihnen Beachvolleyball-Klamotten anziehen. [DeReKo]

b. Er zieht sich an und redet wie ein Wessi. [DeReKo]

1 Man beachte aber die bereits oben erwähnte spätere Abkehr Fillmores (1977) von Rollendefinitionen, die auf sortale Eigenschaften der Partizipanten Bezug nehmen.

2 Nur am Rande sei angemerkt, dass Engel sein eigenes Unterscheidungskriterium nicht immer konsequent anwendet. So klassifiziert er die NG die beiden in Man schloss die beiden aus dem Turnverein aus (Engel 1991: 364) als OBJ, obwohl es sich offenbar um menschliche und reaktionsfähige Partizipanten (und damit wohl um PAT im Engel'schen Sinne) handelt. 
Offenbar ist es sinnvoll, die Ausdrücke ihnen in (29)(a) und sich in (29)(b) einander als Realisierungsstrukturen desselben Aktanten zuzuordnen. In diesem Falle kommt man zu dem Schluss, dass es zu einer Schwankung in der Realisierungsstruktur (Akkusativ/ Dativ) kommt, die bei typischen patientiven Aktanten (wie z. B. das Haus in das Haus abreißen) nicht vorkommt. Wir schließen daraus, dass im A-2Bereich tatsächlich - neben Patiens - eine weitere Rolle nötig sein könnte, die reaktionsfähige, bei der Handlung „kooperierende“ Partizipanten kennzeichnet. In (29) ergibt sich der Bedarf an einer solchen Rolle zum einen aus der Notwendigkeit, die Ausdrücke ihnen und sich einander zuzuordnen, was bei einer einheitlichen Vergabe der Rolle „Patiens“ an die AkkE nicht möglich wäre, zum anderen aus dem Bedürfnis, die formale Alternation Akk/Dat rollentheoretisch zu begründen. ${ }^{1}$ Wir wählen zu diesem Zweck allerdings nicht wie Engel das gewöhnlich anders besetzte Rollenlabel „Patiens“, sondern das Label „Rezipient“ (vgl. auch Abschn. 4.1). Als „Rezipient“ wären damit auch die anderen kursiv hervorgehobenen Begleiter in den Beispielen unter (28) zu betrachten. Die Zuordnung zu einer Position im Aktantenrahmen schwankt dabei zwischen A-2, vgl. (a)-(c), und A-3, (d)-(h). In (28)(h) hätten wir es mit einem „negativen Rezipienten“ zu tun, also mit einem Partizipanten, dem etwas genommen wird (vgl. Abschn. 1, Punkt 3, und 4.1).

Halten wir als Zwischenergebnis der Diskussion fest, dass uns die meisten bei Engel (1991) vorgeschlagenen Rollendistinktionen grammatisch nicht relevant zu sein scheinen. Ein auf der Prototypen-Theorie beruhendes Patiens-Konzept, wie es etwa Welke (2011) oder Primus (2012) vorschlagen, scheint für unsere Zwecke ausreichend zu sein. Mit Primus (2012: 31 f.) könnten wir „Patiens“ als die Rolle des physisch von der Handlung betroffenen oder sich verändernden Partizipanten bestimmen, wobei die Belebtheit oder Reaktionsfähigkeit dieses Partizipanten zunächst keine Rolle spielt. Vom Konzept des Proto-Patiens nehmen wir allerdings mit Blume (2000) und Primus (2012) Partizipanten aus, denen durch die Bedeutung des Valenzträgers entweder eine aktive, kooperative Beteiligung an der bezeichneten Situation oder aber überhaupt keine spezifische Involvierung in das Geschehen auferlegt wird. Im ersten Fall sprechen wir von „Rezipienten“, im zweiten Fall von „Referenzgrößen“ (vgl. das Konzept „thematischer Partizipant" bei Blume 2000: 170 f.). Daneben ist zu berücksichtigen, dass in der A-2-Position auch „Experiencer“ oder „Stimuli“ (vgl. Abschn. 2.4) realisiert werden können.

1 Der Vollständigkeit halber muss allerdings darauf hingewiesen werden, dass die Dativ-Markierung des Drittaktanten von anziehen nicht als markiertes Linking im Sinne von Blume (2000) bezeichnet werden kann, da der Dativ in dreistelligen Aktantenrahmen nach Blume gerade den unmarkierten Normalfall darstellt. 


\subsection{Thema, Patiens und Rollenkombinationen}

Die letzte Rolle, die wir in diesem Abschnitt noch diskutieren wollen, ist die besonders in der angloamerikanischen Literatur weit verbreitete Rolle "Theme“, hier als "Thema“ eingedeutscht. Die Rolle geht auf das lokalistische Rollenkonzept von Gruber zurück (vgl. hierzu Welke 2011: 142-144) und wird gewöhnlich als „an entity to which the verb's meaning assigns a location or a change of location“ (Fillmore 2003: 464) definiert. Wenn man statische und dynamische Rollen unterscheidet, wie wir dies in Abschn. 2.2 getan haben, engt sich das Konzept auf Ortswechsel („change of location“) ein. Das „Thema“ eines Valenzträgers wäre demnach ein Partizipant, der sich von einem Ort an einen anderen Ort bewegt (vgl. z. B. Levin und Rappaport Hovav 2005: 49). Die Definition wirft zwei Fragen auf: (a) Kann man Bewegung als Zustandsänderung auffassen und „Thema“ damit unter „Patiens“ subsumieren? (b) Ist Bewegung eine Proto-Patiens- oder eine ProtoAgens-Eigenschaft und "Thema“" somit A-1 oder A-2?

Die erste Frage (a) wird explizit bei Fillmore (2003: 467) formuliert und berührt tiefgreifende konzeptionelle Entscheidungen, die Auswirkungen auf das gesamte Rollenrepertoire haben. Wie bereits oben angedeutet, gibt es Rollenkonzeptionen, die alle thematischen Distinktionen auf räumliche Konfigurationen zurückführen, wobei durch metaphorische Ausweitung die nicht-lokalen Bedeutungen einbezogen werden. Das konkurrierende Rollenkonzept, das mit den Basisrollen "Agens“ und „Patiens“ arbeitet, geht dagegen von kausalen Bezügen als Grundlage für die Modellierung der thematischen Relationen aus (für eine erhellende Diskussion der Konzeptionen vgl. Jackendoff 1990: 25-27; Fillmore 2003; Levin und Rappaport Hovav 2005, Kap. 4.1 und 4.3, oder erneut Welke 2011).

Vor diesem Hintergrund könnte die gleichzeitige Verwendung von „Thema“ und „Patiens“ als redundant, wenn nicht sogar als theoretisch inkonsistent erscheinen. Es gibt allerdings Gründe, die Distinktion zwischen "Zustandsänderung“ und „Bewegung“ bzw. „Ortsveränderung“ aufrecht zu erhalten. Zum einen scheinen bei Aktanten, die als „Thema“ zu bewerten sind, Alternationen vorzukommen, die bei „Patiens“ unseres Wissens nicht auftreten. So kann z. B. das Thema der Werfen-Relation sowohl im Deutschen ${ }^{1}$ als auch im Tschechischen entweder mit strukturellem Kasus im Akkusativ oder mit lexikalischem Kasus (Instrumental) bzw. in einer mit-PG realisiert werden:

(30) a. Peter wirft mit Steinen. [konstruiert]

b. Petr hází kameny. [konstruiert]

1 Bemerkenswerter Weise ist die Realisierung in einer mit-Gruppe im Deutschen nur im Plural unauffällig ('Peter wirft mit einem Stein), im Tschechischen dagegen in beiden Numeri gleich akzeptabel (Petr hodi kamenem M. M.). Der Unterschied wäre in unserem kontrastiven Valenzlexikon zu dokumentieren, eine Erklärung dafür haben wir momentan nicht anzubieten. 
Eine analoge Alternation ist mit einem typischen Patiens wie etwa Haus in Peter baut ein Haus nicht möglich (*Peter hat mit dem Haus abgerissen / weitergebaut). $\mathrm{Ob}$ solche Unterschiede zwischen Thema und Patiens bei Alternationen wirklich regelmäßig auftreten, wird erst die Auswertung einer größeren Menge an lexikalischem Material zeigen. Im gegenwärtigen Kontext ist jedoch wichtig festzuhalten, dass sich solche etwaigen Unterschiede nur dann erfassen lassen, wenn man Thema und Patiens getrennt hält.

Zum anderen ist die Wertung von „Bewegung" als Patiens-Eigenschaft weniger eindeutig als dies bei „Veränderung" der Fall ist, womit wir bereits bei Frage (b) sind. Dowty (1991: 572) rechnet „Bewegung“ den Proto-Agens-Eigenschaften zu, präzisiert die Zuordnung allerdings dahingehend (S. 574), dass es sich dabei um Bewegungen handeln muss, die nicht durch einen weiteren Partizipanten verursacht werden. Demzufolge würde Dowty der SubE in Sätzen wie Die Wolke zog an den Bäumen vorbei oder Das Wasser füllte den Kanister (dt. R. W. nach den Beispielen in Dowty) die Proto-Agens-Eigenschaft „Bewegung“ zuweisen, nicht aber dem Zweitaktanten von Verben der Bewegungsinduktion wie mit Steinen / kameny in (30), die in diesem Abschnitt der eigentliche Gegenstand unserer Betrachtung sind. Primus (1999: 52) und im Anschluss daran auch Blume (2000: 170) schließen daraus, dass die eigentliche charakteristische Eigenschaft von „Patiens“ bzw. "Thema" nicht in bestimmten semantischen Schattierungen der Rolle, sondern in der Abhängigkeit von einem Agens besteht.

Die Definition von Patiens/Thema als abhängiger Partizipant entspricht der europäischen Tradition, kann aber, wie in Abschn. 1 bereits angedeutet, von uns nicht übernommen werden, da sie für die Identifizierung thematisch ähnlicher Aktanten über die Derivationsgrenzen hinweg nicht geeignet ist. Damit ergibt sich für uns das Problem, wie man dem doppelten Charakter der thematischen Eigenschaft „Bewegung“ als Proto-Patiens- und Proto-Agens-Eigenschaft gerecht werden kann. Wir wählen eine Lösung, die der Konzeption in Jackendoff (1990), Van Valin und Wilkins (1996) und Kaufmann (2004) nahe steht. In den zitierten Arbeiten wird „Agentivität“ bzw. „Kontrolle“ als semantischer Überbau zu weiteren, grundlegenden thematischen Eigenschaften wie „Aktivität“ oder „Bewegung" betrachtet und lässt sich demnach mit diesen Eigenschaften kombinieren. Entsprechend lassen wir in unserem Valenzlexikon in bestimmten Fällen Rollenakkumulation bei einem Aktanten zu, wobei die Kombination „Thema“ und „Agens“ die wohl wichtigste Rollenkombination ist. ${ }^{1}$ Das „Thema“ eines VT kann also gleichzeitig das „Agens“ des VT sein, und zwar immer dann, wenn die Bewegung auf eine Eigenaktivität

1 Weitere Kombinationen wären etwa Rezipient-Agens bei annehmen und Origo-Agens bei abgeben, vgl. Jackendoff (1990: 126 f.). Welche Rollen im Valenzlexikon notiert werden (ob je eine der Komponenten des zusammengesetzten Labels oder beide), ergibt sich aus den jeweils benötigten Kontrasten, z. B. beim Unterscheiden bestimmter Varianten desselben Lexems. Vorrang hat die speziellere Rolle, d. h. Rezipient oder Origo. 
zurückgeht (und der Partizipant damit gleichzeitig die Definition von "Agens“ und "Thema“ erfüllt). In diesem Fall wird die Rolle, wie bereits eingangs anhand von Beispiel (2) demonstriert (unten erneut als (31) aufgeführt), in verbalen aktivischen Konstruktionen einheitlich auf die Subjektposition ${ }^{1}$ abgebildet. Ohne Kombination mit der Agens-Rolle kann „Thema“ - je nach der Anwesenheit eines weiteren, agentiven Aktanten - entweder auf die Subjektposition ( $\mathrm{a} / \mathrm{b})$ oder auf die Objektposition (c) abgebildet werden.

(31) Als sie sich weigerten, den Platz zu räumen, wurden sie festgenommen. [DeReKo]

(32) a. Das Wasser läuft ins Becken. [konstruiert]

b. Das Wasser füllt den Kanister. [konstruiert nach Dowty 1991]

c. Peter wirft den Stein ins Wasser. [konstruiert]

Die Kombinierbarkeit der Rollen „Agens“ und „Thema“ liefert uns ein weiteres Argument dafür, die Rollen „Thema“ und „Patiens“ distinkt zu halten: Eine analoge Kombination "Agens-Thema“ wie in Die Demonstranten räumen den Platz oder Peter geht nach Hause ist unseres Wissens für „Agens“ und „Patiens“ nicht möglich (*Agens-Patiens). Kein Verb im Deutschen oder Tschechischen, sofern nicht durch Reflexivierung eine Rollenidentifizierung syntaktisch herbeigeführt wird, ${ }^{2}$ weist einem Partizipanten gleichzeitig die Rolle des Eigenaktivität entfaltenden Urhebers einer Situation und des im Verlauf derselben Situation die Beschaffenheit ändernden Vorgangsträgers zu.

Rollenakkumulation ist in unserem Beschreibungssystem, das sich im Prinzip auf das klassische Rollenkonzept von Fillmore (1968) stützt, zugegebener Maßen ein systemfremdes Element. Nach Fillmore dürfen Rollen weder akkumuliert werden, noch dürfen sie (wie bei uns „Ferens" und wohl auch „Thema“ wie z. B. bei folgen) in einem Rahmen mehrfach vorkommen (vgl. auch das Theta-Kriterium bei Chomsky 1981). Für die kohärente Integration der oben angestellten Überlegungen in ein geschlossenes Modell wäre vermutlich die Abkehr von einem System mit festem Rollenrepertoire und die Hinwendung zu Ansätzen, die mit Mehr-Ebenen Systemen (Jackendoff 1990; Grimshaw 1990), Rollen-Dekomposition (Reinhart 2002), thematischen Proto-Eigenschaften (Dowty 1990; Primus 1999; Blume 2000) oder Prädikaten-Dekomposition (Levin und Rappaport Hovav 1995; Van Valin und LaPolla 1997; Kaufmann 2004) arbeiten, notwendig. Mit der Wahl eines der alternativen Beschreibungsmodelle würden wir aber wegen der großen Komplexität aller neueren Vorschläge unweigerlich in Konflikt mit dem ersten der eingangs formulierten Ziele, nämlich

1 Ob die kombinierte Thema-Agens-Rolle im Aktantenrahmen auf die A-1-Position oder auf die A-2-Position abgebildet werden muss, ist eine schwierige Frage, die wir hier nicht weiter erörtern können. Vermutlich wird man für eine Entscheidung die Wahl des Auxiliars in der Perfektkonstruktion (Die Demonstranten haben den Platz geräumt $\times$ Die Demonstranten sind der Konfrontation mit der Polizei ausgewichen) berücksichtigen müssen (vgl. z. B. Grewendorf 1989).

2 Mit marginalen Ausnahmen. Hier wäre v. a. baden zu nennen, das auch ohne sichtbare Reflexivierung eine Aktivität bei gleichzeitiger Zustandsänderung (nachweisbar durch die Resultativkonstruktion Ich bin gebadet) bezeichnet. Die prinzipielle Möglichkeit der Reflexivierung (sich baden) legt den Verdacht nahe, dass auch hier die Syntax beteiligt ist. 
mit dem Ziel der Anschaulichkeit und Benutzerfreundlichkeit, geraten. Uns erscheint die oben gewählte Kompromisslösung daher als das kleinere Übel und wir müssen die kohärente Deutung unserer Notation der weiterführenden Forschung überlassen.

\section{Rollen im Bereich des Drittaktanten}

\subsection{Rezipienten und Adressaten}

Charakteristisch für diese Position ist, dass der Partizipant anhand des vom Prädikat bezeichneten Ereignisses zum Besitzer einer Entität wird. Mit anderen Worten empfängt (lat. recipit) er etwas, er wird also zum „Rezipienten“. Diese Rolle wird in linguistischen Arbeiten unterschiedlich behandelt. So ordnet z. B. Engel (1991) dem Dativ bei Verben des Besitzwechsels und der Kommunikation, wie bereits erwähnt, nicht die Rolle „Rezipient“, sondern die Rolle „Patiens“ zu, was wohl lediglich als terminologische Besonderheit zu vermerken ist, die keinerlei linguistische Konsequenzen nach sich zieht (vgl. die Ausführungen in Abschn. 3.2). Entsprechende Beispiele sind uns in (33a) und dir in (33b):

(33) a. Der Staat schenkt uns Steuern. [Engel 1991: 371]

b. Jetzt habe ich dir alles erzählt. [Engel 1991: 365]

Primus (2012: 45) bemerkt, dass die Rolle „Rezipient“ gelegentlich als Adressat näher eingegrenzt wird. Der Rezipient zeichne sich (ebd.) durch eine hybride Akkumulation von thematischen Eigenschaften (Proto-Rollen-Eigenschaften) aus. Als Besitzer bzw. „Experiencer“ verfügt er über eine agentivische Komponente, steht aber zugleich durch seine Zustandsveränderung und kausale Affiziertheit dem Patiens nahe. Die Rolle „Adressat“ (statt Rezipient) ist z. B. bei Helbig (1983: 95) zu finden. Bei Panevová et al. (2014: 48) wird „Adressat" als dritte Valenzposition mit der kognitiven Rolle eines Geschehensempfängers charakterisiert. In [PMČ, S. 384] ist dagegen nur die Rolle „Rezipient“ (Empfänger von etwas) zu verzeichnen, die anhand von zwei Beispielsätzen demonstriert wird: Já to řeknu učiteli ,Ich sage es dem Lehrer" und Jana dala matce růže ,Jana hat der Mutter Rosen gegeben`.

Für unseren Bedarf halten wir es für nützlich, die Rolle „Rezipient“ einzuführen, die wir im Einklang mit Primus (2012: 44) als Empfänger einer Entität oder Information bei Verben des Besitzwechsels und der Kommunikation verstehen. Die formale Realisierung der Rezipientenrolle ist dabei sehr breit gefächert. Sie kann als Objekt im Dativ, (34a), als Objekt im Akkusativ, (34b), oder als Präpositionalobjekt, (34c), realisiert werden.

(34) a. Max schenkte seinem Opa einen Motorroller. [Primus 2012: 46]

b. Max versorgt seine Großeltern mit Getränken. [Primus 2012: 46]

c. Max verschenkte seinen Roller an Opa. [Primus 2012: 46] 
Bei den Verben bekommen, erhalten und kriegen steht der Rezipient im Nominativ, (35a). Mit Engel (1991: 375) könnte man auch einen „negativen Rezipienten“ wie bei verlieren Ansetzen, (35b), wobei dann allerdings die Unterscheidung zur Rolle „Origo“ / „Ursprungsort“ (vgl. Abschn. 5.2) undeutlich wird. Die Abgrenzung muss auf die Eigenaktivität oder zumindest des Eigeninteresse des Partizipanten („Proto-Agens-Eigenschafen“) Bezug nehmen, die dem Verlust (in Beispiel (35b) dem Verlust der Uhr) entgegenstehen und bei „Ursprungsorten“ nicht gegeben sind.

(35) a. Max bekam von Opa einen rührenden Brief.

b. Uta hat ihre Uhr verloren. [BKS, S. 610]

\subsection{Co-Agens als Aktant oder Zirkumstant?}

Die Charakteristik der Rolle „Rezipient“ als aktive und kooperierende Größe kann bei einigen Valenzträgern bis zur fast gleichwertigen Beteiligung am Geschehen mit dem Agens hinüberwachsen. Es handelt sich v. a. um solche Prädikate, die einen Austausch von Informationen enthalten wie im Beispiel (36):

(36) Ich habe mit Meiers über ihren Urlaub gesprochen. [Engel 1991: 370]

Die dermaßen kooperierende Größe wird, wie aus dem Beispiel ersichtlich, häufig durch eine PG mit + Dat ausgedrückt. Ihre gleichwertige Stellung mit dem Agens innerhalb des Geschehens lässt sich durch die Umformung entsprechender Beispielsätze zu Konstruktionen mit pluralischem Subjekt sichtbar machen: jmd. spricht mit jmdm. > Sie sprechen miteinander; jmd. spielt mit jmdm. > Sie spielen miteinander; jmd. tanzt mit jmdm. > Sie tanzen miteinander; jmd. kämpft mit jmdm. $>$ Sie kämpfen miteinander. Diese Tatsache erlaubt uns, die entsprechenden Begleiter als Sonderfall von "Rezipient“ aufzufassen und sie terminologisch als „Co-Agens“ zu einer eigenen Rolle zusammenzufassen. Es ist in diesem Zusammenhang zu bemerken, dass die Eigenschaft einiger Prädikate, den Zweit- bzw. Drittaktanten die gleiche Funktion wie dem Agens zuzuweisen, vor Jahren bereits Schröder (1992) und Engel (1991) festgestellt haben. Bei Schröder (1992: 27) wird die Rolle „CoAgens“, die als semantische Kasusfunktion (abgekürzt CO-AG) gekennzeichnet ist, bei der Beschreibung von Präfixverben verwendet. Es handelt sich um eine Gruppe von Verben mit be-Präfix (kommunikative Verben) und um eine Gruppe von Verben mit ver-Präfix (Verben, die einer Kontaktbeziehung von mindestens zwei Personen bezeichnen). Im ersten Fall gibt Schröder (1992:74) an, dass eine PG mit + Dat realisiert wird: Der Professor berät mit seinen Assistenten die Arbeit. Eine Zusammenfassung von Agens und Co-Agens ist möglich: Sie beraten (miteinander) die Arbeit. Im zweiten Fall sind Agens und Co-Agens laut Schröder (1992: 214) primär in einer einzigen pluralischen Form zu realisiert: Sie verabreden, sich $z u$ 
treffen. Wenn aber eine der beiden Personen als Agens eine gewisse Dominanz hat, so erscheinst das Co-Agens laut Schröder als PG: Er verabredet sich mit ihr (für den nächsten Tag).

Im Zusammenhang mit der Rolle CO-AG stellt sich allerdings auch die Frage, wie Begleiter zu behandeln sind, die zwar einen aktiv an der Handlung partizipierenden Partizipanten bezeichnen, andererseits aber keine Umstrukturierung des Aktantenrahmens durch Reflexivierung zulassen. Beispiele für solche „Komitative“, auf die wir bei der Korpus-Recherche für das geplante Valenzlexikon gestoßen sind, finden sich in (37):

(37) a. Schrepfer war mit seiner Freundin für zwei Wochen Ferien nach Kanada geflogen. [DeReKo]

b. So packt der Weltenbummler nun wieder die Koffer und zieht mit seiner Frau und den beiden südvietnamesischen Adoptivkindern [...] erneut gen Osten. [DeReKo]

c. Jacqueline und Hanspeter Eggenberger sind mit drei Buben eingezogen. [DeReKo]

In allen Fällen kann der Begleiter, der in (37) in einer mit-Gruppe realisiert ist, durch Konjunktion an die Subjektposition angeschlossen werden (Schrepf und seine Freundin, der Weltenbummler und seine Frau, Jacqueline, Hanspeter und die drei Buben), ohne dass jedoch die im Zusammenhang mit (36) erwähnte Reflexivierbarkeit vollständig gegeben wäre (?acqueline und die Buben sind miteinander eingezogen).

Es ließe sich argumentieren, dass die Symmetrie bei der Beteiligung an der Handlung von (a) zu (c) abnimmt, ohne dass sie (im Falle der Kinder) völlig schwindet. Unsymmetrisch wird das Prädikat allerdings dann, wenn die Position in der mit-Gruppe durch einen Ausdruck ohne Kontrolleigenschaften besetzt wird; in diesem Falle ist auch, sieht man von Wortspielen und ironisierenden Kontexten ab, keine Koordination in der Subjektposition mehr möglich (vgl. Dowty 1991 für ein ähnliches Beispiel unter Reflexivierung):

(38) a. Mit nur wenig Gepäck war Madeleine Aubron in die Kollwitzstraße eingezogen. [InterCorp]

b. *Madeleine und ihr Gepäck waren in der Kollwitzstraße eingezogen. [konstruiert]

Man könnte nun entweder aus der Koordinierbarkeit des Begleiters in der mitGruppe in (37) schließen, dass es sich um einen Aktanten mit der Rolle CO-AG handelt, wodurch man - trotz der formalen Identität - einen Rollenkontrast zu (38) etablieren würde. Umgekehrt könnte man allerdings auch die formale Identität zum Anlass nehmen, um von einer ebensolchen Identität des Aktantenrahmens auszugehen und dann auf Grundlage von (38) die mit-Gruppe in beiden Fällen als Zirkumstanten zu betrachten. Für die zweite Lösung sprechen Kontexte wie (39), 
in denen kontrollfähige und nicht-kontrollfähige Partizipanten koordiniert in einer mit-Gruppe erscheinen:

(39) Lidé se stěhovali do podzemní dráhy s nábytkem, dětmi i psy. [SYN2015]

Die Leute zogen in die U-Bahn-Schächte ein, mit Möbeln, Kindern und Hunden. [Übers. RW]

Da die Koordination von CO-AG mit Zirkumstanten nach den üblichen methodologischen Prinzipien als ausgeschlossen gelten muss, dürften die Kinder, trotz der möglichen Koordination im Subjekt als die Leute und ihre Kinder, in (39) nicht als CO-AG betrachtet werden. In Folge würde man dann auch die Co-AG-Analyse von (37) verwerfen.

Dem stehen allerdings Argumente gegenüber, die direkt mit der kontrastiven Konzeption unseres Valenzlexikons zu tun haben. Wertet man nämlich Belege aus parallelen Korpora aus, trifft man die Situation, die wir bei (37) als methodisches Testverfahren verwendet haben, unmittelbar in der sprachlichen Realität an. In (40) findet sich eine Übersetzungs-Parallele aus [InterCorp]:

(40) Právě jsme se nastěhovali s Geirem ke klukovi, který se jmenuje Stig Inge. Geir und ich sind gerade bei Stig Inge eingezogen. [InterCorp]

Würde man die mit-Gruppe im Tschechischen (s Geirem) als Zirkumstant werten, bliebe völlig unklar, woher das Koordinat Geir in der Subjektposition der deutschen Parallelstelle kommt. Betrachtet man die mit-Gruppe im Tschechischen dagegen als Realisierung von CO-AG, dann macht die Fusion mit AG in der deutschen Parallele (sofern man eine entsprechende Realisierungsregel an der Hand hat) Sinn. ${ }^{1}$

Um den sich oben abzeichnenden Widerspruch zwischen einer Analyse als CO-AG und dem eher an einen Zirkumstanten erinnernden Verhalten der mitGruppe (Fakultativität, weitgehend beliebige Hinzufügbarkeit, andere semantische Konnotationen als bei der mit-Gruppe bei Verben im Kernbereich, z. B. bei debattieren, kämpfen oder sich treffen) aufzulösen, bietet sich eine Kompromisslösung an. Bei Verben wie denen in (36) etc. könnte man Co-Agens als Position im Zentrum des Aktantenrahmens (A-2 oder A-3) ansetzen, bei denen in (37) dagegen eine Valenz-Erweiterungsposition mit (unter bestimmten Bedingungen ergänzbaren) Co-Agentien vorsehen.

1 Die genaue strukturelle Parallele zur tschechischen Konstruktion im Deutschen (wir mit Geir) wäre kein geeignetes Übersetzungsäquivalent, weil die Konstruktion im Tschechischen - im Unterschied zur genauen Nachahmung im Deutschen - nicht impliziert, dass es eine Sprechergruppe gibt, der eine weitere Person (Geir) angeschlossen wird. Die Gruppe, die im Tschechischen durch die 1. Ps. Pl. bezeichnet wird, besteht mit an Sicherheit grenzender Wahrscheinlichkeit wirklich nur aus dem Sprecher und Geir. Insofern muss die Parallele in [InterCorp] als kommunikativ vollständig äquivalent betrachtet werden, keineswegs als übersetzungsbedingte Verzerrung. 


\section{Periphere Rollen}

Die Bezeichnung „periphere Rollen“ verwenden wir hier im doppelten Sinne. Zum einen handelt es sich um semantisch sehr spezifische Rollen, die in der Forschungsliteratur nur wenig verbreitet sind und daher einen "peripheren Status“ haben. Ein typisches Beispiel ist die Rolle FIN („Finalergänzung“), die bei Engel (1991) verwendet wird. Hier ist zu überlegen, ob solche Rollen für die Erfassung der valenztheoretisch relevanten Eigenschaften der Lexeme benötigt werden oder ob man sie unter andere, weitläufiger definierten Rollen subsumieren bzw. als Zirkumstanten vernachlässigen kann. Zum anderen bezeichnen wir Rollen als „peripher“, wenn sie außerhalb des grammatisch aktiven Bereichs des Aktantenrahmens, d. h. außerhalb des Bereichs von Erst-, Zweit- und Drittaktant angesiedelt sind. Hier sind v. a. lokale Rollen wie „Lokativ“ oder „Direktiv“ zu nennen. Einer peripheren Rolle im ersten Sinne (nämlich FIN) ist Abschn. 5.1 gewidmet, mit den lokalen Rollen beschäftigt sich Abschn. 5.2.

\subsection{Finalergänzung}

Bei Engel (1991: 362-377) finden sich in einer Liste von mehr als hundert deutschen Verben mit ihren Bedeutungsbeschränkungen insgesamt 23 Beispielsätze, die nach Ansicht des Autors die relationale Bedeutung „Finalergänzung“ FIN (Zweck) aufweisen. Aus formaler Sicht handelt es sich meistens um Präpositionalgruppen (an, zu, um, nach, für), weniger häufig aber auch um Substantive im Akkusativ und schließlich um Infinitiv- und Inhaltssätze. Beispiele (mit Seitenangaben, die sich auf Engel 1991 beziehen) finden sich in (41):

(40) a. Holger arbeitet an seinem Öffentlichkeitsbild. [S. 363].

b. Mein Vetter hat dich völlig aufgegeben. [S. 363].

c. Ich würde Ihnen $z u$ diesem Schlafzimmer raten. [S. 370]

d. Er riet mir zum Nachgeben. [S. 370]

e. Ich habe ihn zu einem neuen Wohnzimmer überredet. [S. 374]

f. Wir haben Sie von der Ehrlichkeit unserer Absicht überzeugt. [S. 374]

g. Es kam zu einer schlimmen Auseinandersetzung. [S. 366]

h. Das Parlament stimmte geschlossen für die Erhöhung der Renten. [S. 373]

Die erste Frage, die sich hier stellt, ist die Frage nach dem Aktantenstatus der Begleiter. Handelt es sich wirklich um Aktanten (Ergänzungen) oder doch eher um Zirkumstanten (Angaben)? Als erste Instanz für eine Entscheidung dieser Frage könnte man den Eliminierungstest (Helbig 1992103 f.) heranziehen und prüfen, ob die Beispiele auch nach der Streichung des Begleiters (bei konstanter Bedeutung) grammatisch bleiben. Der Test liefert folgendes Bild: 
(42) a. Holger arbeitet.

b. "Mein Vetter hat völlig aufgegeben.

c. 'Ich würde Ihnen raten.

d. 'Er riet mir.

e. Ich habe ihn überredet.

f. Wir haben Sie überzeugt.

g. *Es kam.

h. *Das Parlament stimmte geschlossen.

Das Symbol „\#“ bei (42)(b) markiert die veränderte Bedeutung des modifizierten Beispiels, die Fragezeichen deuten an, dass entsprechende Sätze evtl. bei habitueller Lesart akzeptabel sind, wobei aber Sätze in habitueller Lesart generell keine diagnostischen Kontexte darstellen (Jacobs 1994: 315) und das Testergebnis für (42)(c) und (42)(d) damit als negativ gelten kann. Dasselbe gilt für (42)(g) und (42)(h). Die Sätze (42)(a), (42)(e) und (42)(f) sind dagegen voll akzeptabel, womit an seinem Öffentlichkeitsbild, zu einem neuen Wohnzimmer und von der Ehrlichkeit unserer Absicht - zumindest nach diesem Test - als Zirkumstanten gelten müssten.

Da der Eliminierungstest alleine für sich noch nicht aussagekräftig ${ }^{1}$ ist, v. a. dann, wenn man auch Fakultativität bei der Realisierung von Aktanten zulässt (Helbig 1992: 104 f.; Ágel 2000: 241) und umgekehrt auch mit (kommunikativ) obligatorischen Zirkumstanten rechnet (Sgall, Hajičová und Panevová 1986: 130; Žabokrtský und Lopatková 2007: 47; Welke 2011: 88), bedarf es einer Ergänzung. Als letzte Instanz für die Beurteilung des Valenzcharakters der FIN-verdächtigen Begleiter werden wir daher die Ausführungen von Panevová et al. (2014: 52 f., 64) in Betracht ziehen. In dieser Arbeit wird der Unterschied zwischen INTT (kurz für „Intention“) als Quasi-Ergänzung und AIM („Ziel“) als Angabe demonstriert, vgl. (43). Beide Satelliten können als Entsprechungen der von uns hier diskutierten Rolle FIN gelten.

(43) a. Velitel poslal své lidi na pomoc při hašení požáru. [Panevová et al. 2014: 53] Befehlshaber schicken.3SG.Prät seine Leute auf Hilfe.INTT bei Löschen Brand

b. ,Der Kommandant schickte seine Leute, um beim Löschen des Brandes zu helfen'

(44) a. Velitel poslal své lidi pro pomoc při hašení požáru [Panevová et al. 2014: 53] Befehlshaber schicken.3SG.Prät seine Leute für Hilfe.AIM bei Löschen Brand

b. ,Der Kommandant schickte seine Leute, um Hilfe beim Löschen des Brandes zu holen'

Panevová et al. machen darauf aufmerksam, dass zwischen (43) und (44) ein Unterschied bei der lexikalisch angewiesenen Koreferenz zwischen dem Patiens des Matrixverbs (seine Leute) und dem Agens der eingebetteten Nominalisierung

1 Kritisch bereits Helbig (1992: 85), wo sich auch eine genauere Darstellung von ergänzenden bzw. präzisierenden Testkontexten findet. 
besteht. Während in (43) das Agens des Nomen Agentis pomoc ,Hilfe` obligatorisch koreferent mit dem Patiens des Matrixverbs poslat, schicken' ist, ist in (44) das Agens des Nomen Agentis pomoc nicht referenzidentisch mit dem Patiens des Matrixverbs: Es sind nicht die geschickten Leute, die helfen sollen, sondern andere, die von diesen Leuten zur Hilfe geholt werden sollen. Unter der Annahme, dass die Koreferenz im Lexikoneintrag des übergeordneten Prädikats festgelegt sein muss (vgl. den Begriff, „Kontrolle“ bei Chomsky 1981: 74-79), ergibt sich aus dem Gesagten, dass INTT in (43) ein Aktant ${ }^{1}$ von poslat, schicken' sein muss, da sonst im Lexikoneintrag von poslat, schicken' nicht Bezug auf die entsprechende Position genommen werden könnte. Umgekehrt braucht AIM in (44) nicht als Aktant von poslat ,schicken' gewertet werden, da keine Kontrollrelation vorliegt und daher im Lexikoneintrag von poslat, schicken' auch nicht Bezug auf die Position AIM genommen werden muss. Der Versuch von Panevová et al. für poslat ,schicken`im Tschechischen lässt sich bei unseren Beispielen auch für das Deutsche reproduzieren.

(45) a. Holger arbeitet daran, sein Öffentlichkeitsbild zu verbessern / an der Verbesserung seines Öffentlichkeitsbildes.

b. Ich würde Ihnen zum Kauf dieses Schlafzimmers raten / dieses Schlafzimmer zu kaufen.

c. Wir haben ihn überredet ein neues Bett zu kaufen / zum Kauf eines neuen Bettes überredet.

d. Wir haben sie überzeugt uns zu besuchen / vom Besuch dieses Theaterstückes.

Die Sätze (45)(a)-(45)(c) würden den Aktantenstatus der Begleiter erweisen, da der implizite Erstaktant des Infinitivs und des Verbalsubstantivs immer mit einem bestimmten Aktanten des Matrixverbs referenzidentisch sein muss und daher im Sinne von Chomsky (1981) und Panevová et al. (2014) als kontrolliert gelten kann. Lediglich bei (45)(d) sind Zweifel angebracht, da Kontexte denkbar sind, in denen der Erstaktant von Besuch nicht mit dem Zweitaktanten von überzeugen referenzidentisch sein muss. (Die Vertreter der Stadt waren von dem regen Besuch der Vorstellung überzeugt und sagten die weitere Finanzierung des Theaters $z u$ bedeutet ,dass so viele Menschen die Vorstellung besucht haben', nicht ,dass die Vertreter der Stadt die Vorstellung besucht hatten'.) Zudem kommen bei arbeiten und überzeugen Zweifel auf, da die zur Debatte stehende Position durch Ausdrücke besetzt werden kann, die selbst kein Valenzpotential aufweisen (Er arbeitet an einem Roman, Sie hat uns von ihrer Zuverlässigkeit überzeugt) und damit die Kontrollrelation hinfällig wird. Wir betrachten die beiden Verben daher bereits an dieser Stelle nicht als mögliche Träger einer Aktantenrelation FIN, obwohl wir sie der Vollständigkeit halber in der weiteren Diskussion berücksichtigen.

1 INTT wird von Panevová et al. (2014: 52) einem Übergangsbereich zwischen Ergänzungen und Angaben zugeordnet und als „Quasi-Ergänzung" klassifiziert. AIM wäre dagegen eine freie Angabe. 
Nach der Klärung des Aktantenstatus der Begleiter in (41) muss geklärt werden, welche thematische Rolle ihnen zuzuweisen wäre. Unseres Erachtens müsst die Finalität der Ausdrücke, die Engel (1991) intuitiv voraussetzt, explizit durch eine Umformungsprobe nachgewiesen werden, bei der die nominale Ergänzung in einen entsprechenden Finalsatz oder in eine Infinitivkonstruktion mit $u m+z u$ umgeformt wird. Eine weitere Möglichkeit, das Vorliegen der FIN-Relation zu überprüfen, wäre die Erfragung des Satzinhalts mit Hilfe der Fügung „Zu welchem Zweck?“. Da Engel weder die erste noch die zweite Möglichkeit nutzt, soll dies an dieser Stelle nachgeholt werden.

In (46) haben wir versucht, das nominale Satzglied, das in (41) laut Engel eine finale Relation zum Valenzträger ausdrückt, in Finalsätze umzuwandeln:

(46) a. Holger arbeitet, damit sein Öffentlichkeitsbild besser wird.

b. "Mein Vater hat völlig aufgegeben, dass er / damit er ... (?)

c. 'Ich würde Ihnen mit dem Ziel raten, dass Sie sich dieses Schlafzimmer kaufen.

d. Er riet mir, damit ich nachgebe.

e. Ich habe mit ihm geredet, damit er sich ein neues Wohnzimmer kauft.

f. "Wir haben Sie mit dem Ziel überzeugt, dass unsere Absicht ehrlich ist.

g. "Es kam dazu, damit ... (?)

h. Das Parlament stimmte mit dem Ziel ab, dass die Renten erhöht werden.

Wie man unschwer erkennt, hängt der Ausgang des Testes davon ab, wie frei die Paraphrasen gewählt werden dürfen. Für (41)(a), (d), (e), (h) und - mit Einschränkungen - auch für (c) lassen sich, sofern man gewisse Freiheiten wie die Ergänzung von besser in (41)(a) oder die Ersetzung des Partikelverbs überreden durch das entsprechende Basisverb reden in (41)(e) in Kauf nimmt, tatsächlich Paraphrasen finden, die eine finale Bedeutung plausibel machen. Bei (41)(b), (f) und $(\mathrm{g})$ ist uns dagegen unklar, wie sich die von Engel behauptete Finalität durch Umformung nachweisen ließe. Bei (41)(a) scheint uns zudem die lexikalische Besetzung der Position das Testergebnis zu verzerren: Von einem Öffentlichkeitsbild erwartet man, dass es verbessert werden muss und dass dies das Ziel der Arbeit sein kann. Setzt man dagegen ein Objekt ein, das durch Arbeit erst geschaffen werden muss (Roman, Dissertation, Verkabelung, Fassade), liegt wohl eher die Patiensrolle (entstehender Partizipant') nahe, auch wenn man natürlich auch hier (durch die Wendung ,mit dem Ziel, dass ... entsteht') eine finale Paraphrase erzwingen könnte.

Das Bild, das man durch Umformungs- und Fragetest gewinnt, muss insgesamt als unscharf bezeichnet werden. So lassen sich unter den Beispielen in (41) zwar einige (aufgeben, überzeugen, zu etwas kommen) als sicher nicht final aussondern, für den Nachweis des finalen Charakters der verbleibenden Begleiter muss man dann allerdings sehr großzügige Paraphrasen wählen. Wir werden im Folgendem dennoch für die Verwendung der Rolle FIN argumentieren, und zwar aus einem Grund, der sich anhand eines weiteren Engel'schen Beispiels erörtern lässt: 
(47) ist problemlos in eine finale Konstruktion überführbar ( > Anna ruft, damit der Bruder zu ihr kommt > Anna ruft mit dem Ziel, dass der Bruder zu ihr kommt > Anna ruft, um den Bruder herzuholen) und erlaubt eine Frage mit "Zu welchem Zweck?"“ ( $Z u$ welchem Zweck ruft Anna?). Von allen bisher genannten Beispielen scheint hier die Annahme einer spezifischen thematischen Rolle FIN am besten gerechtfertigt zu sein. Dieser Eindruck lässt sich auch durch einen Blick in das Enzyklopädische Deutsch-böhmische Wörterbuch von Sterzinger (1931: 1220) erhärten, wo die Bedeutung des Verbs nach jmdm. rufen mit ,rufen, um ihn herbeikommen zu lassen ‘ umschrieben wird und damit unzweideutig eine finale Bedeutungskomponente (,um ...zu') zugeschrieben erhält. Auch die Paraphrasen in [VALBU] (RUfEN ${ }^{11}$, S. 609), verlangen, dass jemand kommt ' und im [DUDEN]-Wörterbuch (S. 2821) ,rufend nach jmdm. verlangen' weisen in dieselbe Richtung.

Daneben lässt das Verb rufen bekanntlich auch eine AkkE zu, die Engel (1991: 370) als Patiens betrachtet. Die genaue Spezifizierung der Rolle ist im gegenwärtigen Zusammenhang nicht wesentlich (wir würden eher „Rezipient“ ansetzen), wesentlich dagegen ist, dass es sich hier offenbar um zwei verschiedene Varianten des Lexems bzw. (je nach Körnung des Klassifikationssystems) um zwei verschiedene Lexeme im Rahmen eines Hyperlexems handelt. Der lexematische Unterschied schlägt sich nicht nur in der Wahl unterschiedlicher Formmerkmale bei der Valenzrealisierung nieder, was nach unserem Ansatz nicht automatisch das Ansetzen von unterschiedlichen Valenzträgern nötig macht (vgl. Ágel 2000: 127 f.; anders Žabokrtský und Lopatková 2007: 43), sondern auch in Unterschieden bei den Selektionsbeschränkungen der Position. Im Unterschied zur PräpE ist die AkkE (außerhalb von personifizierenden und somit stark markierten Kontexten) nicht durch Ausdrücke mit dem Merkmal [-anim] besetzbar:

(48) Sie rufen nach Wasser. $\times{ }^{*}$ Sie rufen das Wasser.

Der Unterschied zwischen den beiden Lexemvarianten lässt sich auch satzsemantisch begründen. Während es bei rufen+Akk das Ziel der rufenden Person ist, vom Gerufenen gehört zu werden, ist bei rufen+nach das Ziel, einen ungenannten Adressaten dazu zu bewegen, etwas nicht Vorhandenes (z. B. Wasser) herbeizuschaffen. Diese Interpretation lässt sich auch durch die tschechische Übersetzung von entsprechenden deutschen Kontexten erhärten, da im Tschechischen die konative Komponente in der Bedeutungsstruktur des Verbs explizit versprachlicht werden muss: Sie lag in Ohnmacht, man riefnach Wasser / Ležela v mdlobách, volali, aby někdo prinesl vodu (Sterzinger 1931: 1220; wörtl.: ,Sie riefen, dass jemand Wasser bringen solle'); Sie riefen, man solle Wasser holen / Volali, at' prinesou vodu (Übers. M. M., wörtl. ,Sie riefen, dass jemand Wasser holen solle'). 
Wir stellen also fest, dass innerhalb des (Hyper-)Lexems rufen mindestens zwei Varianten zu unterscheiden sind. Nach den eingangs aufgeführten Prinzipien (Abschn. 1) sollten die gewählten thematischen Rollen den Leser des Valenzlexikons dabei unterstützen, die vom Lexikographen getroffene Variantenbildung schnell und klar zu erfassen. Ein solcher Fall liegt hier vor: RUFEN ${ }^{1}$ (mit AkkE) (Agens, Rezipient) und RUFEN ${ }^{2}$ (mit PräpE) (Agens, Final) können - unabhängig vom Formmerkmal des Zweitaktanten - durch den Kontrast zwischen „Rezipient“ und „Final“ eindeutig unterschieden werden, wobei das Rollenlabel FIN gleichzeitig die auf die Ausführung einer Handlung gerichtete Intention des Rufers symbolisiert.

Fassen wir zusammen: Die Größe FIN gehört zwar nicht zu den Aktanten, die den Valenzrahmen ausmachen, ist aber als periphere Rolle zur Erfassung bestimmter Valenzrealisierungs-Strukturen unumgänglich. Für den Valenzcharakter der Größe FIN und somit auch für die Einbeziehung dieser Rolle in unser Rolleninventar spricht letzten Endes die Tatsache, dass der Ersatz der PG mit finaler Bedeutung durch eine AkkE (vgl. Der Kranke rief nach der Schwester $\rightarrow$ Der Kranke rief die Schwester) die zugrunde liegende Satzbedeutung modifiziert, was durch das Ansetzen unterschiedlicher Rollen dokumentiert werden muss.

\subsection{Lokale Ergänzungen (Lokativ)}

„Lokativ“ ist die semantische Rolle für den Ort, an dem die Situation oder ein Partizipant in dieser Situation eingeordnet wird (vgl. Primus 2012: 63). Unter „Lokativ“ werden häufig auch spezifischere lokale Rollen wie „Position“, „Direktiv“ oder "Source“/,Ursprung" subsumiert. So verwenden etwa [BKS, S. 11 f.] das allgemeine Label LOC, das dann durch Subskripte (abl, all, prt, dir) näher bestimmt wird. In der älteren Grammatik von Engel (1991:362-377) kommen die relationalen Merkmale DIR (Richtung) und SIT (Situativbestimmung) vor. Im Folgenden soll es darum gehen, ob Relate mit lokaler Semantik als Aktanten (Ergänzungen) gelten können, wie viele Typen benötigt werden und wie sie ggf. in den Aktantenrahmen $\mathrm{zu}$ integrieren sind.

Lokale Satelliten werden in der germanistischen Tradition gewöhnlich dann als „Ergänzungen“ angesehen, wenn sie obligatorisch ${ }^{1}$ sind (Helbig und Schenkel 1969, zit. 1978: 26; Welke 2011: 56, 87). Typische Beispiele wären Verben der Lokalisierung wie sich befinden, liegen, stehen oder wohnen. De facto wird damit von einer einheitlichen Definition des Begriffes „Ergänzung“ Abstand genommen, da das Kriterium „Obligatheit“ disjunktiv mit anderen möglichen Kriterien (insbes. Subklassenspezifik, Rektion) verwendet wird (Ágel 1995: 22, 25; Welke 2011: 54). In anderen valenztheoretischen Forschungstraditionen (z. B. der tschechischen,

1 Helbig (1992: 74) spricht hier von „notwendig“ und unterscheidet zwischen „obligatorisch“ und „notwendig“ (ebd., S. 99 f.). Wir können und wollen die damalige Debatte zu diesem Thema hier nicht mehr aufgreifen und belassen es daher bei dem Hinweis. 
wie sie sich im Rahmen der Prager Dependenzgrammatik herausgebildet hat, vgl. Sgall, Hajičová und Panevová 1986) spielt die Fakultativität bzw. Obligatheit von Begleitern für die Bestimmung des Aktantenstatus dagegen keine Rolle.

Wir schließen uns der germanistischen Tradition an und betrachten lokale Begleiter dann als Bestandteile des Aktantenrahmens, wenn sie obligatorisch sind, vorausgesetzt, sie bezeichnen Individuen und keine Eigenschaften (schlecht in Mit abgebrochener Mine schreibt es sich schlecht würden wir demnach nicht als Teil des Aktantenrahmens werten, sondern als Modifikator, der aus bestimmten Gründen unter bestimmten Bedingungen kommunikativ notwendig ist, vgl. dazu Welke 2002: 249 f.; 2011: 88). Wie Ágel (1995: 25) schreibt, ist Obligatheit wohl eher ein skalares Konzept. Trotzdem sollte man das Kriterium nicht zu großzügig handhaben: So ist in dem Satz Wir haben hinter diesen Häusern Kartoffeln angebaut von Engel (1991: 223), der das relationale Merkmal SIT veranschaulichen soll, das lokale Adverbiale (binter den Häusern) wohl eher als Lokalangabe, nicht als Aktant zu bestimmen.

Über den Status der Größen SIT und DIR als Aktanten entscheidet letztendlich die Bedeutung des Valenzträgers. So gibt es z. B. Verben wie liegen, die eine Lokalisierung im Raum ausdrücken und eine statische Lokalbestimmung als Ergänzung verlangen, vgl. (49)(a). Bei manchen Fortbewegungsverben muss die Spezifizierung der Richtung als Ausgangs-, Durchgangs- oder Zielpunkt der Fortbewegung im Aktantenrahmen enthalten sein. So implizieren sich begeben und laufen einen Zielpunkt (nach Schröder 1993 LOC GOAL), vgl. (49)(b) und (49) (c), bummeln einen Durchgangspunkt (LOC PATH), vgl. (49)(d), und rauschen (in der Bedeutung als Bewegungsverb) einen Ausgangspunkt (LOC SOURCE), vgl. (49)(e).

(49) a. Prag liegt an der Moldau.

b. Der Schauspieler begab sich aufseinen Platz. [Schröder 1993: 27]

c. Sie läuft jeden Tag ins Wirtshaus. [Schröder 1993:73]

d. Wir bummeln ein wenig durch die Geschäfte [Schröder 1993: 30]

e. Die gekränkte Schauspielerin rauschte von der Bühne. [Schröder 1993: 86]

In unserem Beschreibungsapparat verwenden wir (in Anlehnung an Sgall, Hajičová und Panevová 1986: 124) statt SOURCE das Rollenlabel „Origin“ (abgekürzt ORIGO), vgl. auch Panevová et al. (2014: 57-63). LOC („Lokativ“) benutzen wir nicht, wie Schröder (1993) oder [BKS], als übergeordnete Kategorie für lokale Ergänzungen allgemein, sondern lediglich für statische Lokalbestimmungen. Von solchen statischen LOC grenzen wir mit Hilfe des Labels DIR („Direktiv“) dynamische Lokalbestimmungen ab (vgl. Helbig 1983: 94 f.; Žabokrtský und Lopatková 2007: 48). Unter dieselbe Kategorie fassen wir auch die Dimension ,Durchgangspunkt der Fortbewegung', die bei Schröder als LOC PATH figuriert. 
Die Gemeinsamkeit aller lokalen Ergänzungen, die u. E. vorrangig in der formalen Variabilität und der Immunität gegen grammatische Operationen wie Passivierung oder Nominalisierung besteht (vgl. Grepl und Karlík 1998: 50; Ágel 1995: 23-25; Karlík 2000b: 172, 179), bringen wir dadurch zum Ausdruck, dass die entsprechenden Rollen nicht den zentralen Positionen des Aktantenrahmens (A-1 bis A-3) zugeordnet werden, sondern in der Peripherie (abgekürzt PER) verbleiben. ${ }^{1}$ In bestimmten Fällen, v. a. bei Präfigierung des Valenzträgers (z. B. wohnen/bewohnen) können sie allerdings ins Zentrum aufrücken und werden dann für die gängigen grammatischen Operationen zugänglich. Authentische Beispiele aus [DeReKo] sowie unsere Analyse des entsprechenden Aktantenrahmens, die wir für das geplante Valenzlexikon erstellt haben, finden sich in (50) und (51). Der periphere Aktant mit der Rolle „Lokativ“ (LOC) ist jeweils durch Kursivierung hervorgehoben:

(50) a. Acht Familien haben in dem Haus gewohnt. [DeReKo]

b. Im Erdgeschoss wird grundsätzlich nicht gewohnt. [DeReKo]

c. Zunehmend beliebt wird das Wohnen in Hinterhöfen. [DeReKo]

d. A-1 (Agens), PER (Lokativ)

a. Eine Frau bewohnte eine Wohnung mit Räumen in zwei Etagen. [DeReKo]

b. Kaum ein anderer Raum wird so intensiv bewohnt wie das Kinderzimmer. [DeReKo]

c. Es sollte eine Lösung gefunden werden, damit das Bewohnen der alten Häuser wieder attraktiver wird. [DeReKo]

d. A-1 (Agens), A-2 (Lokativ)

Wie den Beispielen zu entnehmen ist, wird LOC bei wohnen in (50) mit Hilfe einer PG realisiert; die konkrete Form der Realisierung hängt direkt von der beabsichtigten Bedeutung ab und bleibt in allen grammatischen Kontexten (Aktivkonstruktion, Passivkonstruktion, Infinitivnominalisierung) gleich (hier in + Dat). Bei bewohnen in (51) rückt LOC dagegen in die A-2-Position auf und unterliegt den üblichen Realisierungsregeln für Zweitaktanten: in Aktivkonstruktionen mit Hilfe des Akkusativs, in Passivkonstruktionen mit Hilfe des Nominativs und bei Infinitivnominalisierungen mit Hilfe des Genitivs. Durch die Verwendung der thematischen Rolle LOC wird es nunmehr möglich, alle Realisierungsstrukturen einander zuzuordnen und entsprechende Fälle im geplanten Valenzlexikon zu dokumentieren. Damit genügt die Rolle der eingangs in Punkt 2 formulierten

1 Wir greifen damit die Einsicht der Prager Dependenzgrammatik auf, dass (obligatorische) Lokalbestimmungen nicht (wie in der germanistischen Valenztheorie in Anschluss an Helbig und Schenkel 1969 üblicherweise angenommen) einfach Aktanten sind wie die anderen auch und daher vom Zentrum des Aktantenrahmens zu trennen sind. So wird z. B. in Panevová et al. (2014: 57-63) explizit zwischen Aktanten und obligatorischen Angaben unterschieden, wobei letztere zwar im Rahmen erscheinen, nicht jedoch als Aktanten. Hinweise, dass eine differenzierte Betrachtung notwendig ist, finden sich allerdings auch bei Helbig und Kollegen (z. B. Helbig und Schenkel 1969, zit. 1978: 29). 
Forderung, dass die gewählten thematischen Rollen als gemeinsamer Bezugsrahmen für Valenzrealisierungen in verschiedenen syntaktischen Umgebungen (hier: Simplex vs. Präfixverb) brauchbar sein sollten.

Mit der Bestimmung der Rollen FIN, LOC, DIR und ORIGO schließen wir unsere Durchsicht des Rolleninventars und kommen zur Bilanzierung des Gesamtertrags der Diskussion.

\section{Fazit: Das Rolleninventar für DerVal}

Am Ende der Diskussion erscheint es lohnend, die Ergebnisse noch einmal überblicksartig zusammenzustellen. Wir tun dies in Form einer Tabelle, in der alle thematischen Rollen, die wir im Laufe des Artikels besprochen und für notwendig oder zumindest nützlich befunden haben (plus einige geringfügige Ergänzungen), in alphabetischer Reihenfolge mit Kurzdefinitionen und authentischen Beispielen ${ }^{1}$ aufgeführt sind.

\begin{tabular}{|l|l|l|l|}
\hline Ab-kürzung & Benennung & Definition & Beispiel aus [DeReKo] \\
\hline AG & Agens & $\begin{array}{l}\text { Partizipant, der durch seine } \\
\text { Eigenaktivität die Situation } \\
\text { (willentlich oder unbewusst) in } \\
\text { Gang setzt oder erhält. }\end{array}$ & $\begin{array}{l}\text { Der junge Mann sucht ein } \\
\text { Haus, das seinen Bedürfnissen } \\
\text { entsprach. } \\
\text { Die Burg wird derzeit von } \\
\text { Alexandra Freifrau von } \\
\text { Berlichingen bewohnt. }\end{array}$ \\
\hline BEN & Benefizient & $\begin{array}{l}\text { Nutznießer oder Geschädigter } \\
\text { (Malefizient) eines Geschehens. }\end{array}$ & $\begin{array}{l}\text { Suchen Sie dann den passenden } \\
\text { Wein für mich heraus. }\end{array}$ \\
\hline CAUS & Kausator & $\begin{array}{l}\text { Unspezifischer Verursacher } \\
\text { einer Zustandsänderung. }\end{array}$ & $\begin{array}{l}\text { Das Feuer hat den Container } \\
\text { komplett zerstört. }\end{array}$ \\
\hline CO-AG & Co-Agens & $\begin{array}{l}\text { Partizipant, der zusammen } \\
\text { mit dem Agens eigenaktiv } \\
\text { an der Verwirklichung eines } \\
\text { Geschehens beteiligt ist } \\
\text { bzw. der Aktivität des Agens } \\
\text { Widerstand entgegensetzt. }\end{array}$ & $\begin{array}{l}\text { Der Professor berät mit seinen } \\
\text { Assistenten die Arbeit. } \\
\text { Schrepfer war mit seiner } \\
\text { Freundin nach Kanada } \\
\text { geflogen. }\end{array}$ \\
\hline DIR & Direktiv & $\begin{array}{l}\text { Ziel- und Durchgangspunkt } \\
\text { einer Bewegung }\end{array}$ & $\begin{array}{l}\text { St. Nikolaus zieht mit seinem } \\
\text { Gefolge ins Dorf ein. }\end{array}$ \\
\hline EXP & Experiencer & $\begin{array}{l}\text { Partizipant, der einen weiteren } \\
\text { Partizipanten wahrnimmt oder } \\
\text { eine Empfindung hat. }\end{array}$ & $\begin{array}{l}\text { Man freut sich wieder auf das } \\
\text { Training. } \\
\text { Das entlastet die Gerichte und } \\
\text { ärgert die Anwälte. }\end{array}$ \\
\hline
\end{tabular}

1 Die Beispiele stammen aus dem Archiv der geschriebenen Sprache des Deutschen Referenzkorpus (DeReKo) am IDS Mannheim. In einigen Fällen haben wir Kürzungen und kleine Veränderungen vorgenommen, die den Kerngehalt der Beispiele (die durch Fettdruck hervorgehobenen AktantenRealisierungen) nicht berühren. In einigen Fällen führen wir mehrere Beispiele an, in denen sich die Realisierungsstrukturen desselben Aktanten bzw. derselben Rolle formal unterscheiden. Dadurch soll die prinzipielle Unabhängigkeit der hier verwendeten Rollen von den morphosyntaktischen Formmerkmalen demonstriert werden. 


\begin{tabular}{|c|c|c|c|}
\hline Ab-kürzung & Benennung & Definition & Beispiel aus [DeReKo] \\
\hline FER & Ferens & $\begin{array}{l}\text { Statischer Träger einer } \\
\text { Eigenschaft oder einer } \\
\text { Relation zu einem weiteren } \\
\text { Partizipanten. }\end{array}$ & $\begin{array}{l}\text { Seit Wochen stehen Osterhasen } \\
\text { von weiß bis schwarz in den } \\
\text { Regalen. }\end{array}$ \\
\hline FIN & Finalität & $\begin{array}{l}\text { Ziel oder Zweck, auf die das } \\
\text { Geschehen gerichtet ist }\end{array}$ & $\begin{array}{l}\text { Sie lag in Ohnmacht, man rief } \\
\text { nach Wasser. } \\
\text { Peter wurde zum Militär } \\
\text { eingezogen. }\end{array}$ \\
\hline INSTR & Instrument & $\begin{array}{l}\text { Mittel zur Realisierung eines } \\
\text { Geschehens }\end{array}$ & $\begin{array}{l}\text { Das Regime verfolgte politische } \\
\text { Gegner mit Inhaftierung in } \\
\text { Konzentrationslagern. } \\
\text { Womit sie der bislang } \\
\text { unbekannte Täter zerstörte, ist } \\
\text { noch nicht bekannt. } \\
\end{array}$ \\
\hline LOC & Lokativ & Ort & $\begin{array}{l}\text { Acht Familien haben in dem } \\
\text { Haus gewohnt. }\end{array}$ \\
\hline ORIGO & Origin & $\begin{array}{l}\text { Ausgangspunkt einer } \\
\text { Bewegung }\end{array}$ & $\begin{array}{l}\text { Das Gefolge zieht von } \\
\text { der Mozartstraße her ins } \\
\text { Stadtzentrum ein. }\end{array}$ \\
\hline PAT & Patiens & $\begin{array}{l}\text { Partizipant, der einer } \\
\text { Veränderung unterliegt bzw. } \\
\text { verschwindet oder entsteht. }\end{array}$ & $\begin{array}{l}\text { Beim VW Passat fällt die } \\
\text { Drehzahl rapide ab. } \\
\text { Er schreibt auch Essays, } \\
\text { Kurzgeschichten und Artikel. }\end{array}$ \\
\hline REFER & Referenz & $\begin{array}{l}\text { Partizipant, der in einer } \\
\text { Situation anwesend ist, ohne } \\
\text { durch die Bedeutung des } \\
\text { Valenzträgers eine bestimmte } \\
\text { Eigenschaft zu erhalten. }\end{array}$ & $\begin{array}{l}\text { Wenn die Hunde ein Zeichen } \\
\text { bekommen, folgen sie der } \\
\text { Fährte. }\end{array}$ \\
\hline REZ & Rezipient & $\begin{array}{l}\text { Aktiver Empfänger eines } \\
\text { Gegenstandes, einer Leistung } \\
\text { oder Information bzw. auch } \\
\text { Partizipant, dem etwas } \\
\text { entzogen wird. }\end{array}$ & $\begin{array}{l}\text { Dafür soll das Präsidentenamt } \\
\text { der FDP zufallen. } \\
\text { Damit Sie in jeder Situation } \\
\text { richtig angezogen sind. }\end{array}$ \\
\hline STIM & Stimulus & $\begin{array}{l}\text { Wahrnehmungsgegenstand, } \\
\text { Auslöser einer Wahrnehmung } \\
\text { oder Empfindung bei einem } \\
\text { weiteren Partizipanten. }\end{array}$ & $\begin{array}{l}\text { Riesen-Staus auf der Autobahn } \\
\text { ärgern Autofahrer. } \\
\text { Ich verstehe den Leserbrief } \\
\text { immer noch nicht. }\end{array}$ \\
\hline TEMP & Temporal & Zeitliche Lokalisierung & $\begin{array}{l}\text { Am 12. Oktober soll die erste } \\
\text { Mittwochwanderung folgen. }\end{array}$ \\
\hline THEMA & Thema & $\begin{array}{l}\text { Partizipant, der einem } \\
\text { Ortswechsel unterliegt }\end{array}$ & $\begin{array}{l}\text { Der Putz ist hohl geworden und } \\
\text { fällt fast von selber ab. } \\
\text { Wir vom Werkhof wollen auch } \\
\text { kein Laub und räumen das } \\
\text { Laub relativ früh. }\end{array}$ \\
\hline
\end{tabular}

Tab. 1: Thematische Rollen, die im geplanten derivationellen Valenzlexikon (DerVal) verwendet werden. 
Wie unschwer zu erkennen ist, handelt es sich mit 17 thematischen Rollen um ein relativ umfangreiches Rollenrepertoire, umfangreicher, als dies für die linguistische Forschung wünschenswert ist. Die Rechtfertigung dafür ist zum einen in der lexikographischen Ausrichtung des Projekts zu suchen, die eine feinkörnige Erfassung der lexikalischen Semantik der jeweiligen Valenzträger angeraten sein lässt. Zum anderen handelt es sich bei der Zusammenstellung in Tab. 1 um eine Arbeitsversion, und erst die weitere Ausarbeitung des Valenzlexikons wird zeigen, ob alle Möglichkeiten, die das Repertoire bietet, wirklich ausgeschöpft werden können und sollten.

\section{Literatur}

Ágel, Vilmos (1995): Valenzrealisierung, Grammatik und Valenz. In: Zeitschrift für germanistische Linguistik 23/1/1995. S. 2-32.

Ágel, Vilmos (2000): Valenztheorie. Tübingen, Gunter Narr.

Ágel, Vilmos / Fischer, Klaus (2010): 50 Jahre Valenztheorie und Dependenzgrammatik. In: Zeitschrift für germanistische Linguistik 38/2/2010. S. 249-290.

Alexiadou, Artemis / Schäfer, Florian (2006): Instrument subjects are agents or causers. In: Baumer, Donald / Montero, David / Scanlon, Michael (Hg.): Proceedings of the 25th West Coast Conference on Formal Linguistics. Somerville, Cascadilla Proceedings Project. S. 40-48.

Apresjan, Jurij Derenikovič (1974): Лексическая семантика. Синонимические средства языка. Moskau, Nauka.

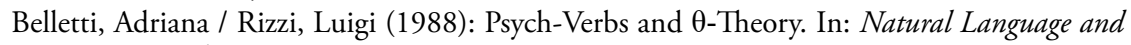
Linguistic Theory 6/3/1988. S. 291-352.

Bierwisch, Manfred (1996): Fragen zum Beispiel. In: Harras, Gisela / Bierwisch, Manfred (Hg.): Wenn die Semantik arbeitet. Klaus Baumgärtner zum 65. Geburtstag. Tübingen, Niemeyer. S. 361-378.

Blume, Kerstin (2000): Markierte Valenzen im Sprachvergleich: Lizenzierungs- und Linkingbedingungen. Tübingen, Niemeyer.

Blume, Kerstin (2004): Nominalisierte Infinitive. Eine empirische Studie zum Deutschen. Tübingen, Niemeyer.

Chomsky, Noam (1981): Lectures on government and Binding. The Pisa Lectures. Zit. nach der 7. Aufl., 1993. Berlin [u. a.], Mouton de Gruyter.

DeLancey, Scott (1984): Notes on agentivity and causation. In: Studies in Language 8/2/1984. S. 181-213.

Dowty, David (1991): Thematic proto-roles and argument selection. In: Language 67/3/1991. S. 547-619.

Eisenberg, Peter (2006): Grundriss der deutschen Grammatik Band 1: Das Wort. 3. Aufl. Stuttgart [u. a.], Metzler.

Engel, Ulrich (1991): Deutsche Grammatik. Heidelberg, Groos.

Engel, Ulrich (2009): Deutsche Grammatik, Neubearbeitung. 2. Aufl. München, Iudicium. Eroms, Hans-Werner (2000): Syntax der deutschen Sprache. Berlin [u. a.], Walter de Gruyter. Fagan, Sarah M. B. (1992): The syntax and semantics of middle constructions. A study with special reference to German. Cambridge [u. a.], Cambridge University Press.

Fillmore, Charles J. (1968): The Case for Case. In: Bach, Emmon / Harms, Robert T. (Hg.): Universals in Linguistic Theory. New York, Holt, Rinehart and Winston. S. 1-88. In dt. 
Übersetzung als „Plädoyer für Kasus“ (übers. Werner Abraham) erschienen in: Abraham, Werner (Hg.): Kasustheorie. (Schwerpunkte Linguistik und Kommunikationswissenschaft, Bd. 2). Frankfurt am Main, Athenäum, 1971. S. 1-118.

Fillmore, Charles J. (1977): The case for case reopened. In: Heger, Klaus / Petöfi, János S. (Hg.): Kasustheorie, Klassifikation, semantische Interpretation. Beiträge zur Lexikologie und Semantik. Hamburg, Buske. S. 3-26.

Fillmore, Charles J. (2003): Valency and semantic roles: the concept of deep structure cases. In: Ágel, Vilmos / Eichinger, Ludwig M. / Eroms, Hans-Werner / Hellwig, Peter / Heringer, Hans Jürgen / Lobin, Henning (Hg.): Dependenz und Valenz / Dependency and Valency: Ein internationales Handbuch der zeitgenössischen Forschung. (= Handbücher zur Sprach- und Kommunikationswissenschaft 25.1). Berlin [u. a.], Walter de Gruyter. S. 457-475.

Grepl, Miroslav / Karlík, Petr (1983): Gramatické prostředky hierarchizace sémantické struktury věty. Brno, Univerzita J. E. Purkyně v Brně.

Grepl, Miroslav / Karlík, Petr (1998): Skladba češtiny. Brno, Votobia.

Grewendorf, Günther (1989): Ergativity in German. Dordrecht, Foris.

Grimshaw, Jane (1990): Argument structure. Cambridge/Mass. [u. a.], MIT Press.

Haiden, Martin (2005): Theta theory. Berlin [u. a.], Mouton de Gruyter.

Hale, Kenneth / Keyser, Samuel Jay (1993): On argument structure and the lexical expression of syntactic relations. In (dies.) (Hg.): The view from building 20. Essays in honor of Sylvain Bromberger. Cambridge/Mass. [u. a.], MIT Press. S. 53-109.

Haspelmath, Martin (1993): More on the typology of inchoative/causative alternations. In: Comrie, Bernard / Polinsky, Maria (Hg.): Causatives and transitivity. Amsterdam [u. a.], John Benjamins. S. 87-120.

Helbig, Gerhard (1983): Studien zur deutschen Syntax. Bd. 1. Leipzig, Enzyklopädie.

Helbig, Gerhard (1992): Probleme der Valenz- und Kasustheorie. Tübingen, Niemeyer.

Helbig, Gerhard / Buscha, Joachim (1999): Deutsche Grammatik. Ein Handbuch für den Ausländerunterricht. 19. Aufl. Leipzig [u. a.]: Langenscheidt / Verlag Enzyklopädie.

Helbig, Gerhard / Schenkel, Wolfgang (1969): Wörterbuch zur Valenz und Distribution deutscher Verben. Leipzig, VEB Bibliographisches Institut. Zit. nach der 4. Aufl. 1978.

Jackendoff, Ray (1990): Semantic Structures. Cambridge/Mass. [u. a.], MIT Press. Zit. nach der 4. Aufl. 1995.

Jacobs, Joachim (1994): Das lexikalische Fundament der Unterscheidung von obligatorischen und fakultativen Ergänzungen. In: Zeitschrift für germanistische Linguistik 22/1994. S. 284-319.

Kailuweit, Rolf (2005): Linking: Syntax und Semantik französischer und italienischer Gefühlsverben. Tübingen, Niemeyer.

Karlík, Petr (2000a): Valence substantiv v modifikované valenční teorii. In: Hladká, Zdeňka / Karlík, Petr (Hg.): Čeština - univerzália a specifika 2. Sbornik konference ve Šlapanicích u Brna 17. - 19. 11. 1999. Brno, Masarykova univerzita. S. 181-192.

Karlík, Petr (2000b): Hypotéza modifikované valenční teorie. In: Slovo a slovesnost 61/ 3/2000. S. 170-189.

Karlík, Petr (2002): Ještě jednou k českým deverbálním substantivům. In: Hladká, Zdeňka / Karlík, Petr (Hg.): Čeština - univerzália a specifika 4. Praha, Nakladatelství Lidové noviny. S. 13-23.

Kaufmann, Ingrid (2004): Medium und Reflexiv. Eine Studie zur Verbsemantik. Tübingen, Niemeyer.

Levin, Beth / Rappaport Hovav, Malka (1995): Unaccusativity. At the syntax-lexical semantics interface. Cambridge/Mass. [u. a.], MIT Press. 
Levin, Beth / Rappaport Hovav, Malka (2005): Argument realization. Cambridge/Mass. [u. a.], Cambridge University Press.

Martin, Fabienne / Schäfer, Florian (2014): Causation at the syntax - semantics interface. In: Copley, Bridget / Martin, Fabienne (Hg.): Causation in grammatical structures. Oxford, Oxford University Press. S. 209-244.

Möller, Max (2007): Psychische Wirkungsverben des Deutschen. In: Deutsch als Fremdsprache 44/1/2007. S. 11-19.

Muzikant, Mojmír / Wagner, Roland (2016): Aktantenidentifizierung in einem derivationellen Valenzlexikon. In: Acta Universitatis Carolinae - Philologica. 4/2016. S. 105-131.

Nedjalkov, Vladimir Petrovič / Jachontov, Sergej Jevgenevič (1988): The typology of resultative constructions. In: Nedjalkov, Vladimir Petrovič (Hg.): Typology of resultative constructions. Amsterdam [u. a.], John Benjamins. S. 3-62.

Panevová, Jarmila / Hajičová, Eva / Kettnerová, Václava / Lopatková, Markéta / Mikulová, Marie / Ševčíková, Magda (2014): Mluvnice současné češtiny. Praha, Karolinum.

Primus, Beatrice (1999): Cases and thematic roles. Ergative, accusative and active. Tübingen, Niemeyer.

Primus, Beatrice (2012): Semantische Rollen. Heidelberg, Winter.

Reinhart, Tanya (2002): The theta system - an overview. In: Theoretical Linguistics 28/3/2002. S. 229-290.

Reinhart, Tanya / Siloni, Tal (2005): The Lexicon-Syntax Parameter: Reflexivization and other arity operations. In: Linguistic Inquiry 36/3/2005. S. 389-436.

Sandberg, Bengt (1976): Die neutrale -(e)n-Ableitung der deutschen Gegenwartssprache. Zu dem Aspekt der Lexikalisierung bei den Verbalsubstantiven. Göteborg, Acta Universitatis Gothoburgensis.

Schippan, Thea (1968): Die Verbalsubstantive in der deutschen Sprache der Gegenwart. Teil In: Deutschunterricht 7/8. S. 422-431. Teil II in: Deutschunterricht 9. S. 516-526.

Schröder, Jochen (1992): Lexikon deutscher Präfixverben. Leipzig, Enzyklopädie.

Schröder, Jochen (1993): Lexikon deutscher Verben der Fortbewegung. Leipzig, Enzyklopädie.

Sgall, Petr / Hajičová, Eva / Panevová, Jarmila (1986): The meaning of the sentence in its semantic and pragmatic aspects. Praha, Academia.

Sonntag, Eric (2004): Argumentrollen und Valenz. Diathetische Aspekte der Pseudoreflexiva. In: Kailuweit, Rolf / Hummel, Martin (Hg.): Semantische Rollen. Tübingen, Gunter Narr. S. 228-247.

Sterzinger, Josef Victor (1931): Enzyklopädisches Deutsch-böhmisches Wörterbuch. III. Teil. Prag, Otto.

Štícha, František (2003): Česko-německá srovnávací gramatika. Praha, Argo.

Van Valin, Robert D. (2005): Exploring the Syntax-Semantics Interface. Cambridge, Cambridge University Press.

Van Valin, Robert Detrick / LaPolla, Randy John (1997): Syntax. Structure, Meaning and Function. Cambridge, Cambridge University Press.

Van Valin, Robert Detrick / Wilkins, David P. (1996): The case for 'Effector': Case roles, agents, and agency revisited. In: Shibatani, Masayoshi / Thompson, Sandra Annear (Hg.): Grammatical constructions. Their form and meaning. Oxford, Clavendon Press. S. 289-322.

Vázquez, María José Domínguez (2011): Kontrastive Grammatik und Lexikographie: spanischdeutsches Wörterbuch zur Valenz des Nomens. München, Iudicium.

Wagner, Roland (in Druck): Zu den Möglichkeiten einer differenzierten Valenztheorie. In: Zukunftsperspektiven der Germanistik. Tagungsband zum XIII. internationalen türkischen Germanistik-Kongress an der Akdeniz-Universität in Antalya. 
Welke, Klaus (1988): Einführung in die Valenz- und Kasustheorie. Leipzig, VEB Bibliographisches Institut.

Welke, Klaus (2002): Deutsche Syntax funktional. Perspektiviertheit syntaktischer Strukturen. Tübingen, Stauffenburg.

Welke, Klaus (2011): Valenzgrammatik des Deutschen. Eine Einführung. Berlin [u. a.], Walter de Gruyter.

Welke, Klaus (2015): Wechselseitigkeit von Valenz und Konstruktion: Valenz als Grundvalenz. In: Engelberg, Stefan / Meliss, Meike / Proost, Kristel / Winkler, Edeltraud (Hg.): Argumentstruktur zwischen Valenz und Konstruktion. Tübingen, Narr Francke Attempto. S. 35-59.

Žabokrtský, Zdeněk / Lopatková, Markéta (2007): Valency information in VALLEX 2.0. Logical structure of the lexicon. In: The Prague Bulletin of Mathematical Linguistics 87/1/2007. S. 41-60.

\title{
Lexikographische Werke und Grammatiken, auf die mit Abkürzungen Bezug genommen wird:
}

[BKS] Djordjević, Miloje / Engel, Ulrich: Wörterbuch zur Verbvalenz Deutsch - Bosnisch/ Kroatisch/Serbisch. München, Iudicium, 2009.

[DUDEN] Das große Wörterbuch der deutschen Sprache in acht Bänden. 2. Aufl. Mannheim [u. a.], Dudenverlag/Bibliographisches Institut, 1993.

[PMČ] Karlík, Petr / Nekula, Marek / Rusínová, Zdenka (Hg.): Príruční mluvnice češtiny. Praha, Lidové noviny, 1995.

[VALBU] Schumacher, Helmut / Kubczak, Jacqueline / Schmidt, Renate / de Ruiter, Vera. Valenzwörterbuch deutscher Verben. (=Studien zur Deutschen Sprache. Forschungen des Instituts für Deutsche Sprache), Band 31. Tübingen, Gunter Narr, 2004.

[VALLEX] Lopatková, Markéta / Kettnerová, Václava / Bejček, Eduard / Vernerová, Anna / Žabokrtský, Zdeněk. Valenčni slovník českých sloves. VALLEX3.0. Praha, Karolinum, 2016.

\section{Elektronische Sprachkorpora}

[DeReKo] Deutsches Referenzkorpus am Institut für deutsche Sprache Mannheim. Archiv der geschriebenen Gegenwartssprache (DeReKo-2015-II, Archiv W). Öffentlich zugänglich über den Korpus-Manager Cosmas II: http://www.ids-mannheim.de/cosmas2/.

[InterCorp] Český národní korpus - projekt paralelních korpusů intercorp. Öffentlich zugänglich unter http://ucnk.korpus.cz/intercorp/.

[SYN2015] Český národní korpus. FF UK, Praha 2015. Öffentlich zugänglich unter http:// www.korpus.cz.

\author{
Mojmír Muzikant und Roland Wagner \\ Katedra německého jazyka a literatura \\ Pedagogická fakulta \\ Masarykova univerzita \\ Poŕíćí 7 \\ CZ-603 00 Brno \\ wagner@ped.muni.cz
}

